\title{
A Novel Emergent State Control Law for an Integrated Helicopter/Turboshaft Engine System
}

\author{
Haibo Zhang, ${ }^{1}$ Yongjin Li, ${ }^{1}$ and S. Deng ${ }^{2}$ \\ ${ }^{1}$ College of Energy and Power Engineering, Nanjing University of Aeronautics and Astronautics, Nanjing 210016, China \\ ${ }^{2}$ Aerodynamic Section, Delft University of Technology, 2629 HS Delft, The Netherlands \\ Correspondence should be addressed to Haibo Zhang; zh_zhhb@126.com
}

Received 8 October 2013; Revised 20 December 2013; Accepted 24 December 2013; Published 11 February 2014

Academic Editor: Yuxin Zhao

Copyright (c) 2014 Haibo Zhang et al. This is an open access article distributed under the Creative Commons Attribution License, which permits unrestricted use, distribution, and reproduction in any medium, provided the original work is properly cited.

\begin{abstract}
A two-layer robust control scheme is proposed to get a better response ability for emergency maneuvers of helicopter. Note that the power used in ascending flight is the main coupling between helicopter and its turboshaft engines; therefore vertical flight control is separated from conventional helicopter control loops and combined with fuel flow and turbine bleeding to new control loops denoted as an inner layer, whereas the mission level flight control is as the out layer. A conclusion in global asymptotically tracking for devising this new scheme is firstly derived from a Generalized Gronwall-Bellman approach. Due to this integrated designing, not only is the helicopter better controlled, but also much better power rapid tracking is realized for engines. Simulations are conducted to validate the new scheme in emergent ascending and descending flights, and the results illustrate that the response time of the closed-loop system is dramatically reduced when compared to the traditional one. Moreover, the presented system also has better dynamic performance under inferences.
\end{abstract}

\section{Introduction}

Since modern aircrafts are highly coupled with their engines, the propulsion system has to be integrated with the flight control system. With the recent development of computer control system, it is a feasible deal with the control problem on modern aircrafts such as STOVL (short taking-off and vertical landing) vehicles [1-3] and helicopters by integrating flight and propulsion systems. Recently, the concept of IFPC (Integrated Flight and Propulsion Control design) has drawn tremendously attention by NASA (National Aeronautics and Space Administration) Glenn research center in developing an autonomous flight/prolusion system $[4,5]$. In helicopter design, the coupling between controllability and propulsion system is mainly from torque variations, which is predominately resulted from the direct mechanical linkages between helicopter and its onboard engine. If the propulsion system cannot rapidly counteract these torque variations from the helicopter, the considerably varying rotor speed will have a dramatical effect on the responsiveness of helicopters
[6-10]. Such circumstance requires a carefully consideration in control system design.

The IFPC problem is an extremely extensive concept in both conventional fixed wing aircrafts and helicopters. The present research will specifically focus on emergency state control. Supported by the famous projects of IHPTET (Integrated High Performance Turbine Engine Technology) and VAATE (Versatile Affordable Advanced Turbine Engines), numerous researches, which focused on fast response control under some emergent conditions, had been initialed by NASA. For emergent conditions such as post-stall flight and forced landing caused by control surfaces failure, the effective control variable (thrust or torque) is individually supplied by engines [11-13]. In order to guarantee a safe landing or correcting angular regulation for aircrafts, the engines have to be operated in an unusual way to enlarge the thrust and response rate. Helicopters and their engines can also encounter the similar conditions, which requires a fast response ability [14, 15]. In 1990s, the Advanced Propulsion System Engine Control (APSEC) project [16] applied a novel 


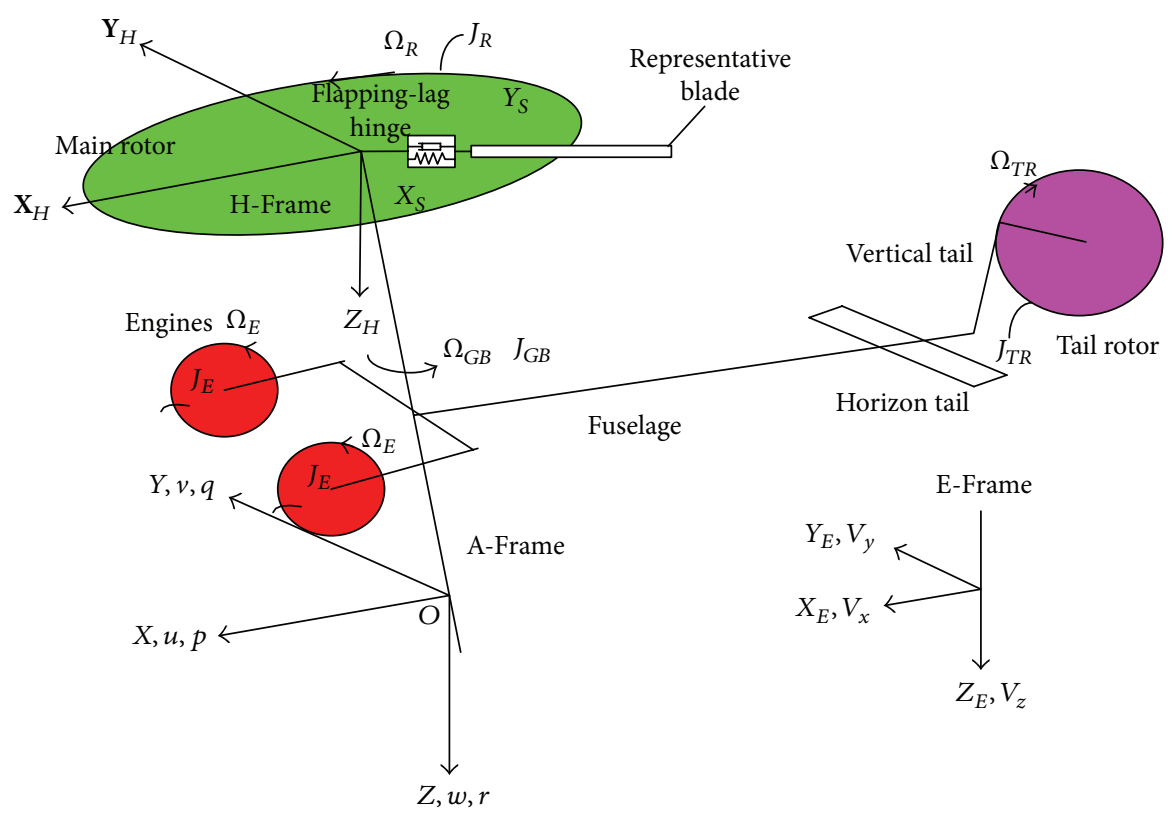

FIgURE 1: The coordinate systems for helicopter flight dynamics.

control method by using fuel flow and compressor guided vanes to regulate the engine's output power, which resulted in a considerable improvement in the agility of helicopters. In the earlier years of this century, for enhancing static and dynamic performance of the integrated system, American armies led an integrated helicopter/engine control program in which a Sikorsky Black Hawk helicopter was selected as the platform [6]. In this program, on the basis of compressor guided vanes regulation with a look-up table, it also showed more feasible to gain a faster response capability in combat modes. Certainly, these air fluid control based approaches have small negative influence on the compressor stall margin. Otherwise, another way by turbine bleeding can also be utilized to devise a fast response control reported in [14], in which an integrated control scheme, implemented by fuel flow, turbine bleeding, and rotor control angles, is developed by aid of LQR (Linear Quadratic Regulator) method. However, such method described does not provide how to realize asymptotically tracking and has not been fully validated over the entire envelop.

In this paper a novel two-layer method is proposed for helicopter's emergent control, so as to promote performance in maneuver ability. This method is an improved one from that reported in [17], where only bounded stability for a Generalized Gronwall-Bellman Lemma approach is investigated for aero engines. Whereas, a conclusion concerning asymptotically tracking is further proposed in our paper. Meanwhile, an UH-60 helicopter with an onboard T700 engine model is employed as the simulation platform. The proposed strategy is verified in terms of robustness in the whole envelope.

The paper is organized as follows. Section 2 discusses the simulation platform of an integrated helicopter and engine system, which is needed in verifying the proposed control scheme. In Section 3, the design method is introduced for emergency flight state. Finally, Section 4 demonstrates the validations by two cases for the new two-layer emergency state control law. For convenience, variables and their annotation are listed in Nomenclature section.

\section{Simulation Platform}

In order to verify the proposed control law, a detailed helicopter/engines system model is required. On the basis of the data and modeling approaches provided and validated in [18-20], an UH-60/T700 system model was built, and for more details about this model one can refer to [21, 22]. The model consists of three major parts: main rotor, air frame, and engine models, as can be seen in Figure 1. The earth, airframe and rotor hub fixed coordinate systems are denoted as E-Frame, A-Frame, and $\mathrm{H}$-Frame, respectively.

2.1. Main Rotor Model. The main rotor of UH-60 helicopter is a single rotor type and can be modelled throughout blade element theory. The relative lift and drag coefficients for blade segments are provided with verified wind tunnel test data $[19,20]$. Through this model, the flapping and lag dynamics, which are the main motions of the main rotor, can be simulated accurately. Furthermore, all the moment and thrust of the rotor, which are responsible for helicopter motions, can also be instantaneously calculated.

2.2. Airframe Model. The airframe is composed by fuselage, horizontal tail, vertical tail, and tail rotor (see Figure 1). The fuselage is modeled on the basis of wind tunnel test data in wide ranges for high angles of attack and sideslip. The horizontal and vertical tail, are treated as aerodynamic 
disks with lift and drag coefficients from look-up tables as a function of attack angles. And the tail rotor model is numerically represented by linearized Bailey theory. For the common case where only the 6 rigid body degrees of freedom are taken into account, the dynamics of helicopter can be expressed as

$$
\dot{\mathbf{X}}_{H}=f\left(\mathbf{X}_{H}, \mathbf{U}_{H}\right),
$$

where the elaborated form is described as

$$
\begin{aligned}
& \dot{u}=\frac{\left(X_{\mathrm{SUM}}-G \sin \theta\right) g}{G}+r v-q w, \\
& \dot{v}=\frac{\left(Y_{\mathrm{SUM}}-G \cos \theta \sin \varphi\right) g}{G}+p w-r v, \\
& \dot{w}=\frac{\left(Z_{\mathrm{SUM}}+G \cos \theta \cos \varphi\right) g}{G}+q u-p v, \\
& \dot{p}=\frac{I_{Z}}{I_{X} I_{X}-I_{X Z}^{2}}\left\{L_{\mathrm{SUM}}-\left(I_{Z}-I_{Y}\right) q r+I_{X Z} p q\right\}+\frac{I_{X Z}}{I_{X} I_{Z}-I_{X Z}^{2}}\left\{N_{\mathrm{SUM}}-\left(I_{Y}-I_{X}\right) p q-I_{X Z} r q\right\}, \\
& \dot{q}=\frac{1}{I_{Y}}\left\{M_{\mathrm{SUM}}-\left(I_{X}-I_{Z}\right) p r+I_{X Z}\left(r^{2}-p^{2}\right)\right\}, \\
& \dot{r}=\frac{I_{X}}{I_{X} I_{Z}-I_{X Z}^{2}}\left\{N_{\mathrm{SUM}}-\left(I_{Y}-I_{X}\right) p q-I_{X Z} r q\right\}+\frac{I_{X Z}}{I_{X} I_{Z}-I_{X Z}^{2}}\left\{L_{\mathrm{SUM}}-\left(I_{Z}-I_{Y}\right) q r+I_{X Z} p q\right\}, \\
& \dot{\theta}=57.3(q \cos \phi-r \sin \phi), \\
& \dot{\psi}=\frac{57.3(r \cos \phi+q \sin \phi)}{\cos \theta}, \\
& \dot{\varphi}=57.3(p+\dot{\psi} \sin \theta) \text {, } \\
& {\left[\begin{array}{c}
\dot{V}_{x} \\
\dot{V}_{y} \\
\dot{V}_{z}
\end{array}\right]=T\left[\begin{array}{c}
\dot{u} \\
\dot{v} \\
\dot{w}
\end{array}\right]} \\
& \mathbf{T}=\left[\begin{array}{ccc}
\cos \psi \cos \theta & \cos \psi \sin \theta \sin \phi-\sin \psi \cos \phi & \cos \psi \sin \theta \cos \phi+\sin \psi \sin \phi \\
\sin \psi \cos \theta & \sin \psi \sin \theta \sin \phi+\cos \psi \cos \phi & \sin \psi \sin \theta \cos \phi-\cos \psi \sin \phi \\
-\sin \theta & \cos \theta \sin \phi & \cos \theta \cos \phi
\end{array}\right],
\end{aligned}
$$

where $\mathbf{X}_{H}=\left[\begin{array}{lllllllll}V_{x} & V_{y} & V_{z} & p & q & r & \varphi & \theta & \psi\end{array}\right]^{T}, \mathbf{U}_{H}=$ $\left[\begin{array}{llll}\theta_{0} & A_{1 c} & B_{1 s} & \theta_{t}\end{array}\right]^{T}$ are defined as state and control vector accordingly. Obviously, the dynamic system (1) can be temporally solved by some integral methods such as Runge-Kutta algorithm. Key parameters for airframe dynamics are given in Table 1.

2.3. Engine Model. T700 engines can supply power to the helicopter for various flights. The engine (see Figure 2) is a two-shaft type consisting of axis compressor, centrifugal compressor, combustion chamber, gas turbine, power turbine, and exhaust nozzle. The engine dynamics are described

\section{TABLE 1: Modeling parameters for airframe motion.}

\begin{tabular}{lc}
\hline Parameter & Value \\
\hline$I_{X}$ & $6316.8 \mathrm{kgm}^{2}$ \\
$I_{Y}$ & $52216.0 \mathrm{kgm}^{2}$ \\
$I_{Z}$ & $49889.0 \mathrm{kgm}^{2}$ \\
$I_{X Z}$ & $2551.7 \mathrm{kgm}^{2}$ \\
$G$ & $73961.0 \mathrm{~N}$ \\
\hline
\end{tabular}

through component level method addressed in [23]. The dynamics of the engine can be formulated as

$$
\dot{\mathbf{X}}_{E}=f\left(\mathbf{X}, \mathbf{U}_{E}\right),
$$




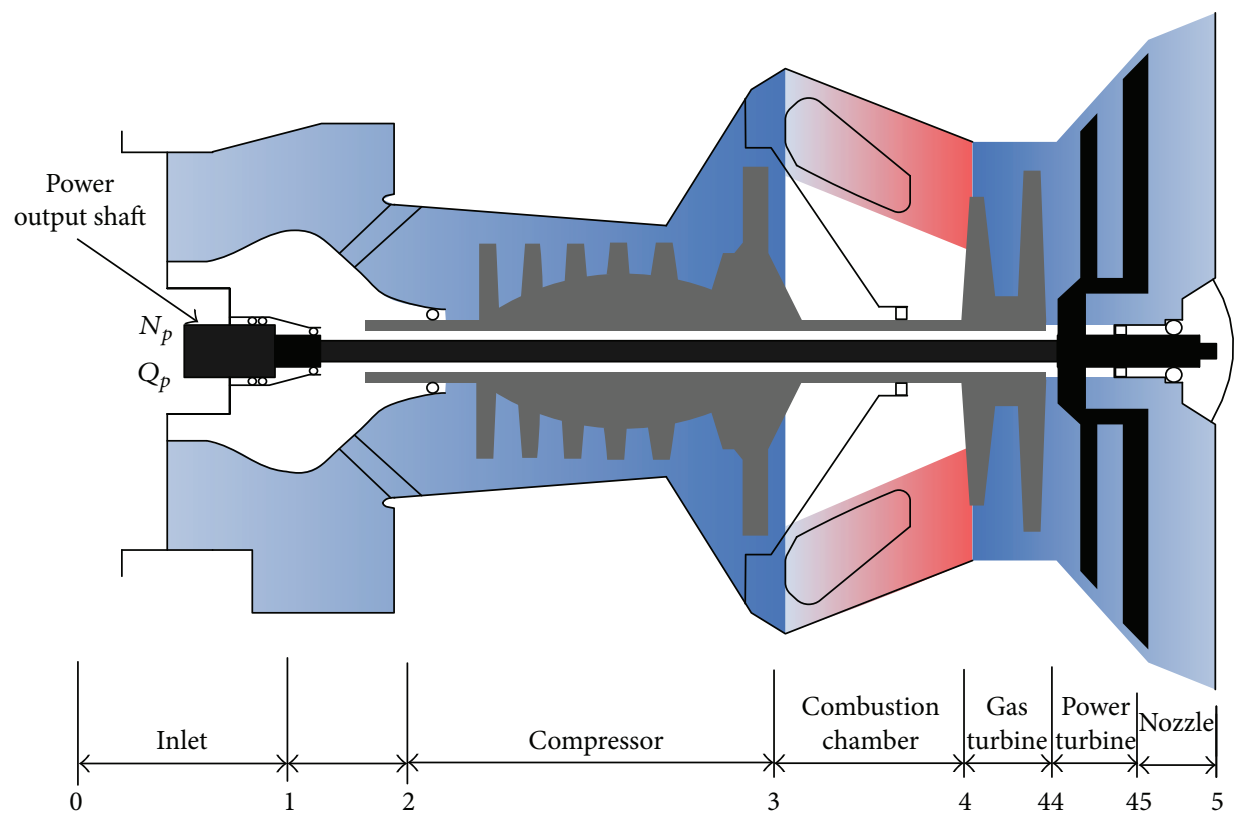

Figure 2: T700 engine structure.

where the detailed expression is

$$
\begin{gathered}
\dot{N}_{p}=\frac{(\pi / 30)^{2}\left(P W_{\text {out }}-P W_{p}\right)}{\left(J_{p} \cdot N_{p}\right)}, \\
\dot{N}_{g}=\frac{(\pi / 30)^{2}\left(P W_{g}-P W_{c}\right)}{\left(J_{g} \cdot N_{g}\right)}, \\
\dot{P}_{4}=\frac{k_{4} R T_{4}}{V_{g}\left(m_{a 3}+W_{f}-m_{g 4}\right)}, \\
\dot{P}_{45}=\frac{k_{45} R T_{45}}{V_{p}\left(m_{g 4}-m_{g 45}-W_{g_{\text {out }}}\right)}, \\
\dot{P}_{5}=\frac{k_{5} R T_{5}}{V_{\mathrm{nz}}\left(m_{g 45}-m_{g 5}\right)},
\end{gathered}
$$

where $\mathbf{X}_{E}=\left[\begin{array}{lllll}N_{g} & N_{p} & P_{4} & P_{45} & P_{5}\end{array}\right]^{T}, \mathbf{U}_{E}=\left[\begin{array}{lll}\theta_{0} & W_{f} & W_{g_{\text {out }}}\end{array}\right]^{T}$ are defined as state and control vector of engine, respectively. $R$ represents gas constant scalar, and $k_{4}, k_{45}$, and $k_{5}$ are denoted as relative adiabatic exponents in different position along the engine flow path. Key modeling parameters for engine dynamics are presented in Table 2.

\section{Design for Fast Response Control Law in Emergence Flight}

For emergent flight normally with a low forward velocity, in which most of power demand comes from vertical flight channel, thus it is possible and necessary to have the vertical flight integrated with engine control loop. In the inner layer of our novel scheme, it can be expressed as an integrated
TABLE 2: Modeling parameters for engine dynamics.

\begin{tabular}{lc}
\hline Parameter & Value \\
\hline$J_{p}$ & $0.064 \mathrm{kgm}^{2}$ \\
$J_{g}$ & $0.085 \mathrm{kgm}^{2}$ \\
\hline
\end{tabular}

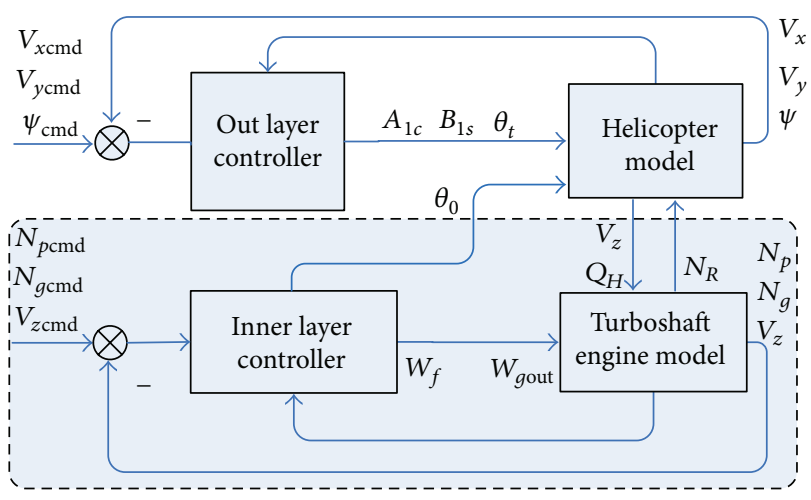

FIGURE 3: Structure of the two-layer control for integrated helicopter/engine system.

helicopter vertical flight/turboshaft controller, which is a 3-3 input and output structure, depicted in Figure 3. The control laws for other flight channels, like forward, sideward, and turn flight, are integrated as out layer control loop.

Obviously, the new scheme is devised differently from the traditional way in which control systems for engines and helicopter are often designed separately. Aiming at weakening the complex dynamic couplings the dynamics of engines and helicopter are taken into account as an integrated one, guaranteeing more feasible and applicable controllers. 
Note that this new control must embody some necessary aspects in a maneuver flight as (1) the power demand of flight reflected by vertical velocity; (2) stability for power transmission guaranteed by keeping power turbine speed constant; (3) fast regulation of gas turbine speed to get a rapid power supply of engines. Considering a much better robustness and adaptive capability for the whole envelope, a novel control law for nonlinear plants is proposed and the followed structure is chosen to design the fast response controller for the integrated helicopter and engine system (see Figure 3).

3.1. Principle of the Proposed Multivariable Robust Control Law. The followed formulations can be employed to describe a nonlinear dynamic model for a helicopter or its engine working in a wider envelop as

$$
\begin{gathered}
\dot{\mathbf{x}}=\mathbf{A x}+\mathrm{G}_{1}(\mathbf{x})+\mathrm{B}_{1} \mathbf{u}+\mathrm{B}_{2} \mathbf{w} \\
\mathbf{y}=\mathbf{C} \mathbf{x}+\mathrm{G}_{2}(\mathbf{x})+\mathrm{D}_{1} \mathbf{u}+\mathrm{D}_{11} \mathbf{w}
\end{gathered}
$$

where $\mathbf{x}, \mathbf{y}, \mathbf{u}$, and $\mathbf{w}$ are denoted as the state, output, control, and disturbance vectors, respectively, and $\mathbf{A}, \mathbf{B}_{1}, \mathbf{C}, \mathbf{D}_{1}$, $\mathbf{B}_{2}$, and $\mathbf{D}_{11}$ are the system matrices relatively. $\mathbf{G}_{1}(\mathbf{x})$ and $\mathbf{G}_{2}(\mathbf{x})$ are defined as nonlinear error functions between the nonlinear plant and its simplified linear one.

The control aim is that system output $\mathbf{y}$ is capable of asymptotically tracking the command signal $\mathbf{c m d}$ such that

$$
\lim _{\mathbf{t} \rightarrow \infty}\|\mathbf{e}\|=\lim _{\mathbf{t} \rightarrow \infty}\|\mathbf{c m d}-\mathbf{y}\|=\mathbf{0}
$$

where $\mathbf{e}=\mathbf{c m d} \mathbf{-} \mathbf{y}$ is defined as output error.

Furthermore, if using $\overline{\mathbf{x}}=\left[\int_{0}^{t} \mathbf{x} d \tau\right]$ as an argument vector and providing that $\mathbf{c m}$ is a set point command, system (5) is reformulated as

$$
\begin{gathered}
\dot{\overline{\mathbf{x}}}=\overline{\mathbf{A}} \overline{\mathbf{x}}+\overline{\mathbf{G}}_{1}(\mathbf{x})+\overline{\mathbf{B}}_{1} \overline{\mathbf{u}}+\overline{\mathbf{B}}_{2} \overline{\mathbf{w}}+\overline{\mathbf{B}}_{3} \widetilde{\mathbf{w}}, \\
\mathbf{z}_{1}=\overline{\mathbf{y}}=\overline{\mathbf{C}}_{\mathbf{1}} \overline{\mathbf{x}}+\overline{\mathbf{G}}_{2}(\mathbf{x})+\overline{\mathbf{D}}_{1} \overline{\mathbf{u}}+\overline{\mathbf{D}}_{11} \overline{\mathbf{w}}, \\
\mathbf{z}_{2}=\overline{\mathbf{C}}_{2} \overline{\mathbf{x}}+\overline{\mathbf{D}}_{2} \overline{\mathbf{u}},
\end{gathered}
$$

where $\overline{\mathbf{G}}_{1}(\mathbf{x})=\left[\begin{array}{c}\mathbf{G}_{1}(\mathbf{x}) \\ -\mathbf{G}_{2}(\mathbf{x})\end{array}\right], \overline{\mathbf{G}}_{2}(\mathbf{x})=\mathbf{G}_{2}(\mathbf{x}), \overline{\mathbf{u}}=\mathbf{u}, \overline{\mathbf{w}}=\mathbf{w}, \overline{\mathbf{y}}=\mathbf{y}$, $\overline{\mathbf{A}}=\left[\begin{array}{cc}\mathrm{A} & 0 \\ -\mathrm{C} & 0\end{array}\right], \overline{\mathbf{B}}_{1}=\left[\begin{array}{c}\mathrm{B}_{1} \\ -\mathrm{D}_{1}\end{array}\right], \overline{\mathbf{B}}_{2}=\left[\begin{array}{c}\mathrm{B}_{2} \\ -\mathrm{D}_{11}\end{array}\right], \overline{\mathbf{C}}_{1}=\left[\begin{array}{ll}\mathrm{C} & 0\end{array}\right], \overline{\mathbf{D}}_{1}=\mathrm{D}_{1}$, and $\overline{\mathbf{D}}_{11}=\mathbf{D}_{11}$.

Assuming that a feedback control law is given as $\overline{\mathbf{u}}=$ $\overline{\mathbf{K}} \overline{\mathbf{x}}$, a theorem for convergent performance about tracking problems can be gotten as follows.

\section{Theorem 1. If the following conditions are held as}

(A) there exists an integer $q \geq 1$ such that $\left\|\overline{\mathbf{G}}_{1}(\mathbf{x})\right\|=$ $\left\|\left[\begin{array}{l}\mathbf{G}_{1}(\mathbf{x}) \\ \mathbf{G}_{2}(\mathbf{x})\end{array}\right]\right\| \leq \gamma\|\mathbf{x}\|^{q}$,

(B) all the eigenvalues of $\overline{\mathbf{A}}+\overline{\mathbf{B}}_{1} \overline{\mathbf{K}}_{1}$ have a strictly negative real part,

(C) the initial state $\overline{\mathbf{x}}_{0}$ satisfies $\left\|\overline{\mathbf{x}}_{0}\right\|^{q-1}<|\lambda| / \gamma M^{q}$, where the constants $M>0$ and $\lambda<0$ are determined by $\left\|e^{\overline{\mathbf{A}}+\overline{\mathbf{B K}}}\right\|<M e^{\lambda t}, \forall t>0$.
Then, a globally convergent tracking of $\lim _{\mathbf{t} \rightarrow \infty}\|\mathbf{c m d}-\mathbf{y}\|=$ $\lim _{\mathbf{t} \rightarrow \infty}\|\mathbf{e}\|=\mathbf{0}$ will be realized.

Proof. Based on the Generalized Gronwall-Bellman lemma from [17], if the above three conditions (A)-(C) were all held for system (7), the state $\overline{\mathbf{x}}=\left[\int_{0}^{t} \mathbf{x} d \tau\right]$ is bounded by

$$
\|\overline{\mathbf{x}}\|<\frac{M\left\|x_{0}\right\| e^{\lambda t}}{\left(1-\gamma M^{q}\left\|x_{0}\right\|^{q-1} /|\lambda|\right)^{1 /(q-1)}} .
$$

Fortunately for general engines and helicopters [17], condition (A) is held such that there exists an integer $q \geq 1$ such that $\left\|\overline{\mathbf{G}}_{1}(\mathbf{x})\right\|=\left\|\left[\begin{array}{l}\mathbf{G}_{1}(\mathbf{x}) \\ \mathbf{G}_{2}(\mathbf{x})\end{array}\right]\right\| \leq \gamma\|\mathbf{x}\|^{q}$.

Condition (B) can be satisfied by some feedback control design methods; here Lemma 2 in the following is introduced to meet this condition.

For helicopters and engines, due to some physical constraints as speed up and burn out limits condition (C) also can be easily checked such that $\left\|\overline{\mathbf{x}}_{0}\right\|^{q-1}<|\lambda| / \gamma M^{q}$.

Hence $\left\|\int_{0}^{t} \mathbf{e} d \tau\right\|<+\infty$, we also know a fact that $e \in L_{2}$ from Lemma 2. Based on the famous Barbalat's Lemma [24] a finite limit can be gotten as

$$
\lim _{\mathbf{t} \rightarrow \infty}\|\mathbf{e}\|=\lim _{\mathbf{t} \rightarrow \infty}\|\mathbf{c m d}-\mathbf{y}\|=\mathbf{0} .
$$

As discussed in Theorem 1, the following lemma is used to meet condition (3) and get the proper feedback control law.

Thus, consider the linear dynamic part for system (5) as

$$
\begin{gathered}
\dot{\mathbf{x}}=\mathbf{A x}+\mathrm{B}_{1} \mathbf{u}+\mathrm{B}_{2} \mathbf{w}, \\
\mathbf{y}=\mathbf{C} \mathbf{x}+\mathrm{D}_{1} \mathbf{u}+\mathrm{D}_{11} \mathbf{w}, \\
\dot{\overline{\mathbf{x}}}=\overline{\mathbf{A}} \overline{\mathbf{x}}+\overline{\mathbf{B}}_{1} \overline{\mathbf{u}}+\overline{\mathbf{B}}_{2} \overline{\mathbf{w}}, \\
\mathbf{z}_{1}=\overline{\mathbf{y}}=\overline{\mathbf{C}}_{1} \overline{\mathbf{x}}+\overline{\mathbf{D}}_{1} \overline{\mathbf{u}}+\overline{\mathbf{D}}_{11} \overline{\mathbf{w}}
\end{gathered}
$$

In order to evaluate a controllable output, a new virtual output is defined as

$$
\mathrm{z}_{2}=\overline{\mathbf{C}}_{2} \overline{\mathbf{x}}+\overline{\mathbf{D}}_{2} \overline{\mathbf{u}}, \quad \overline{\mathbf{C}}_{2}=\left(\begin{array}{c}
\Lambda^{1 / 2} \\
0
\end{array}\right), \quad \overline{\mathbf{D}}_{2}=\left(\begin{array}{c}
0 \\
\mathbf{R}^{1 / 2}
\end{array}\right),
$$

where two weighted matrices are $\boldsymbol{\Lambda}^{\mathrm{T}}=\boldsymbol{\Lambda}>\mathbf{0}$ and $\mathbf{R}^{\mathrm{T}}=\mathbf{R}>$ 0 .

For the augmented system (11), a $H_{2} / H_{\infty}$ robust control method [25-27] can be applied to get the state feedback controller $\overline{\mathbf{K}}$, which yields the transfer function matrix from $\overline{\mathbf{w}}$ to $z_{1}$ as $\left\|\mathbf{T}_{\overline{\mathbf{w}} \mathbf{z}_{1}}\right\|_{\infty}<\gamma$. Moreover, let the quadratic performance index $\mathbf{J}=\int_{0}^{\infty}\left(\overline{\mathbf{x}}^{\mathbf{T}} \boldsymbol{\Lambda} \overline{\mathbf{x}}+\overline{\mathbf{u}}^{\mathbf{T}} \mathbf{R} \overline{\mathbf{u}}\right) \mathbf{d t}$ be as small as possible.

The object of the above problem can be solved by Lemma 2. For further analysis, the system (11) can be converted into the form as

$$
\begin{gathered}
\dot{\overline{\mathbf{x}}}=\overline{\mathbf{A}} \overline{\mathbf{x}}+\overline{\mathbf{B}}_{1} \overline{\mathbf{u}}+\overline{\mathbf{B}}_{2} \overline{\mathbf{w}}+\overline{\mathbf{B}}_{3} \widetilde{\mathbf{w}} \\
\mathbf{z}_{1}=\overline{\mathbf{C}}_{1} \overline{\mathbf{x}}+\overline{\mathbf{D}}_{1} \overline{\mathbf{u}}+\overline{\mathbf{D}}_{11} \overline{\mathbf{w}} \\
\mathbf{z}_{2}=\overline{\mathbf{C}}_{2} \overline{\mathbf{x}}+\overline{\mathbf{D}}_{2} \overline{\mathbf{u}}
\end{gathered}
$$


where $\widetilde{\mathbf{w}}$ stands for a virtual disturbance, $\|\widetilde{\mathbf{w}}\|_{2}<\gamma_{\mathrm{w}} \in$ $R^{+}$holds, and $\overline{\mathbf{B}}_{3}$ is a proper dimensional matrix yielding mathematical solution for this problem. To proceed, a lemma about system (10) is introduced here.

Lemma 2. For system (13) and a specific scalar $\gamma_{1}>0$, provided that the followed Linear Inequality Matrices are held, $\min \gamma_{2}$,

$$
\begin{gathered}
{\left[\begin{array}{ccc}
\overline{\mathbf{A}} \mathbf{X}+\overline{\mathbf{B}}_{1} \mathbf{W}+\left(\overline{\mathbf{A}} \mathbf{X}+\overline{\mathbf{B}}_{1} \mathbf{W}\right)^{\mathrm{T}} & \overline{\mathbf{B}}_{2} & \left(\overline{\mathbf{C}}_{1} \mathbf{X}+\overline{\mathbf{D}}_{1} \mathbf{W}\right)^{\mathrm{T}} \\
\overline{\mathbf{B}}_{2}^{\mathrm{T}} & -\boldsymbol{\gamma}_{1} \mathbf{I} & \mathbf{D}_{11}^{\mathrm{T}} \\
\overline{\mathbf{C}}_{1} \mathbf{X}+\overline{\mathbf{D}}_{1} \mathbf{W} & \mathbf{D}_{11} & -\boldsymbol{\gamma}_{1} \mathbf{I}
\end{array}\right]<\mathbf{0},} \\
\overline{\mathbf{A}} \mathbf{X}+\overline{\mathbf{B}}_{1} \mathbf{W}+\left(\overline{\mathbf{A}} \mathbf{X}+\overline{\mathbf{B}}_{1} \mathbf{W}\right)^{\mathrm{T}}+\overline{\mathbf{B}}_{3} \overline{\mathbf{B}}_{3}^{\mathrm{T}}<\mathbf{0}, \\
{\left[\begin{array}{cc}
-\mathbf{Z} & \overline{\mathbf{C}}_{2} \mathbf{X}+\overline{\mathbf{D}}_{2} \mathbf{W} \\
\left(\overline{\mathbf{C}}_{2} \mathbf{X}+\overline{\mathbf{D}}_{2} \mathbf{W}\right)^{\mathrm{T}} & -\mathbf{X}
\end{array}\right]<\mathbf{0},}
\end{gathered}
$$$$
\text { Trace }(\mathbf{Z})<\gamma_{2} \text {. }
$$

Moreover, if there are optimal solutions of $\mathbf{X}, \mathbf{Z}$, and $\mathbf{W}$ for the above LMIs problem, $\overline{\mathbf{u}}=\overline{\mathbf{K}} \overline{\mathbf{x}}=\mathbf{W}(\mathbf{X})^{-1} \overline{\mathbf{x}}$ is the $H_{2} / H_{\infty}$ controller for system (5).

Furthermore, an equivalent form called quasi-PID (Proportional Integration Difference) is often used as (see [28])

$$
\mathbf{u}=\mathbf{K}_{\mathbf{X}} \mathbf{x}+\mathbf{K}_{\mathrm{e}} \int_{0}^{\mathrm{t}} \mathrm{ed} \tau \text {. }
$$

Proof.

(a) The first LMI in expression (14) guarantees the performance index $H_{\infty}$ yield $\left\|\mathbf{T}_{\overline{\mathbf{w}} \mathbf{z}_{1}}\right\|_{\infty}<\gamma_{1}$.

(b) Due to

$$
\begin{aligned}
\mathbf{J} & =\int_{\mathbf{0}}^{\infty}\left(\overline{\mathbf{x}}(\mathbf{t})^{\mathrm{T}} \boldsymbol{\Lambda} \overline{\mathbf{x}}(\mathbf{t})+\overline{\mathbf{u}}(\mathbf{t})^{\mathrm{T}} \mathbf{R} \overline{\mathbf{u}}(\mathbf{t})\right) \mathbf{d t} \\
& =\int_{0}^{\infty} \mathbf{z}_{2}(\mathbf{t})^{\mathrm{T}} \mathbf{z}_{2}(\mathbf{t}) \mathbf{d t}=\left\|\mathbf{z}_{2}(\mathbf{t})\right\|_{2} .
\end{aligned}
$$

Assuming that sensitive function of closed-loop for system (11) is $\mathbf{T}_{\widetilde{w} z_{2}}(s)$, the flowed inequality can be deduced as

$$
\left\|\mathbf{z}_{2}\right\|_{2}=\left\|\mathbf{T}_{\mathbf{z}_{2} \widetilde{\mathbf{w}}} \widetilde{\mathbf{w}}\right\|_{2}<\left\|\mathbf{T}_{\mathbf{z}_{2} \widetilde{\mathbf{w}}}\right\|_{2} \cdot\|\widetilde{\mathbf{w}}\|_{2}<\gamma_{w} \cdot\|\widetilde{\mathbf{w}}\|_{2},
$$

and this says that $\mathbf{z}_{2} \in L_{2}$.

And a further deduction can be gotten as

$$
\mathbf{x}, \mathbf{y}, \mathbf{e}, \mathbf{u} \in L_{2} .
$$

Thus, the control problem for system (10) can be transferred into a $H_{2} / H_{\infty}$ optimization problem as follows:

$$
\begin{gathered}
\min \gamma_{2}, \\
\left\|\mathbf{T}_{z_{2} \widetilde{w}}\right\|_{2}<\gamma_{2} .
\end{gathered}
$$

Therefore, combined with the conclusions in (a) and (b), the proof for Lemma 2 is completed.
3.2. Two-Layer Robust Control Law for Helicopter's Emergency State. As presented above, for helicopters, a feasible design approach is integrated airframe and engine system control method, so the coupling between them should be well treated. In particular, in the emergency state, we propose a two-layer control law, in which the outer layer is designed for flight control and the inner layer is for engine fast response control. The key problem, or way to deal with couplings, is that vertical control input is calculated in the inner layer. The reason is that the engine has the most influence on the vertical channel, when extra control power, like turbine bleeding, is added in emergency state. The design steps are as follows.

(a) For helicopter, the out layer or flight control system, which is a four-loop control, including forward, sideward, climbing, and yaw flight, can be acquired based on Theorem 1 as

$$
\begin{aligned}
\mathbf{U}_{H} & =\left[\begin{array}{l}
u_{H 1} \\
u_{H 2} \\
u_{H 3} \\
u_{H 4}
\end{array}\right]=\left[\begin{array}{c}
\theta_{0} \\
A_{1 s} \\
B_{1 c} \\
\theta_{t}
\end{array}\right] \\
& =\mathbf{K}_{H X} \mathbf{X}_{H}+\mathbf{K}_{H e} \int_{0}^{\mathbf{t}} \mathbf{e}_{H} \mathbf{d} \tau .
\end{aligned}
$$

(b) For engines, the inner layer control also can be designed by Theorem 1 . As discussed in the front sections, this new scheme is a control structure in which fuel flow incorporates with turbine bleeding and rotor collective control to track the demand power from helicopter rapidly. The scheme is expressed as

$$
\begin{aligned}
\mathbf{U}_{E} & =\left[\begin{array}{l}
u_{E 1} \\
u_{E 2} \\
u_{E 3}
\end{array}\right]=\left[\begin{array}{c}
\theta_{0}^{\prime} \\
W_{f} \\
W_{g_{\text {out }}}
\end{array}\right] \\
& =\mathbf{K}_{E x} \mathbf{X}_{E}+\mathbf{K}_{E e} \int_{0}^{\mathbf{t}} \mathbf{e}_{E} \mathbf{d} \tau .
\end{aligned}
$$

(c) Now, it is easy to find that both (15) and (20) have the main rotor collective input. Since the main coupling item is $V_{Z}$ channel, we choose the control input $\theta_{0}^{\prime}$ in (20) as the final controller's output. So the two-layer control law turns into the form

$$
\begin{gathered}
\mathbf{U}_{H}=\left[\begin{array}{l}
u_{E 1} \\
u_{H 2} \\
u_{H 3} \\
u_{H 4}
\end{array}\right]=\left[\begin{array}{c}
\theta_{0}^{\prime} \\
A_{1 s} \\
B_{1 c} \\
\theta_{t}
\end{array}\right], \\
\mathbf{U}_{E}=\left[\begin{array}{l}
u_{E 2} \\
u_{E 3}
\end{array}\right]=\left[\begin{array}{c}
W_{f} \\
W_{g_{\text {out }}}
\end{array}\right] .
\end{gathered}
$$

Remark 3. For out layer or flight control, it means imposing an extra disturbance on system input for replacing input $u_{H 1}$ by $u_{E 1}$. Therefore, provided that the closed-loop for helicopter has margin in terms of antidisturbance, it would still keep static and dynamic performance to some extent. Certainly this layer is designed based on Theorem 1, such that good robustness and anti-disturbance ability. 
For inner layer or engine control loops, a similar conclusion may be drawn in terms of robustness and antidisturbance ability. In this case, the demanding power variations, not only decided by vertical climbing but also forward and sideslip flight, can be looked at as an additional system disturbance. Of course, due to its robust design the inner layer can also tolerate this kind of disturbance in this situation.

3.3. Out Layer Control in Emergency Flight. The out layer or flight control system for UH-60 helicopter is implemented in this section, and the system state, control input, and system output are introduced, respectively, as follows:

state vector for helicopter is $\mathbf{x}_{H}=$ $\left[\begin{array}{lllllllll}V_{x} & V_{y} & V_{z} & p & q & r & \phi & \psi & \theta\end{array}\right]^{T}$,

$$
\begin{aligned}
& \text { control input vector is } \mathbf{U}_{H}=\left[\begin{array}{lllll}
\theta_{0} & A_{1 c} & B_{1 s} & \theta_{t}
\end{array}\right]^{T} \text {, } \\
& \text { output vector is } \mathbf{y}_{H}=\left[\begin{array}{llll}
V_{x} & V_{y} & V_{z} & \psi
\end{array}\right]^{T} \text {, } \\
& \text { command signal is } \mathbf{c m d}_{H}= \\
& {\left[\begin{array}{llll}
V_{x \mathrm{cmd}} & V_{y \mathrm{cmd}} & V_{z \mathrm{cmd}} & \psi_{\mathrm{cmd}}
\end{array}\right]^{T} \text {, }} \\
& \text { output error vector is } \mathbf{e}_{H}=\mathbf{c m} \mathbf{d}_{H}-\mathbf{y}_{H} \text {, } \\
& \text { disturbance is } w_{H}=\Omega_{R} \text {. }
\end{aligned}
$$

In the hover flight state as $H=0 \mathrm{~m}$ and $V_{x}=V_{y}=$ $V_{z}=0 \mathrm{~m} / \mathrm{s}$, system matrices for the helicopter can be easily identified by perturbation methods [29] as follows:

$$
\begin{aligned}
& \mathbf{A}_{H 1}=\left[\begin{array}{ccccc}
-0.009920 & 0.000789 & 0.019326 & -0.259361 & 5.508862 \\
-0.006006 & -0.074958 & -0.012146 & -5.614851 & -0.242581 \\
0.015424 & -0.009135 & -0.377051 & -0.249239 & 0.415087 \\
-0.022955 & -0.168659 & -0.030995 & -4.149794 & 0.419433 \\
-0.000618 & 0.004887 & 0.019240 & -0.032284 & -0.601711 \\
0.001020 & 0.022554 & 0.018359 & -0.121840 & -0.091497 \\
0.000000 & 0.000000 & 0.000000 & 1.000000 & 0.000000 \\
0.000000 & 0.000000 & 0.000000 & 0.000000 & 0.000000 \\
0.000000 & 0.000000 & 0.000000 & 0.000000 & 1.000000
\end{array}\right] \\
& \mathbf{A}_{H 2}=\left[\begin{array}{cccc}
0.189433 & 0.000000 & 0.000000 & -9.766719 \\
-0.188853 & 9.766719 & 0.000000 & 0.031043 \\
-0.061903 & 0.455786 & 0.000000 & -0.665203 \\
0.157180 & 0.000000 & 0.000000 & 0.000000 \\
-0.074104 & 0.000000 & 0.000000 & 0.000000 \\
-0.307293 & 0.000000 & 0.000000 & 0.000000 \\
0.068109 & 0.000000 & 0.000000 & 0.000000 \\
1.002317 & 0.000000 & 0.000000 & 0.000000 \\
0.000000 & 0.000000 & 0.000000 & 0.000000
\end{array}\right] \\
& \begin{array}{c}
\mathbf{A}_{H}=\left[\begin{array}{llll}
\mathbf{A}_{H 1} & \mathbf{A}_{H 2}
\end{array}\right], \\
\mathbf{B}_{H 1}=\left[\begin{array}{cccc}
0.112449 & -0.019934 & 0.191121 & -0.000000 \\
-0.033941 & 0.197670 & 0.022143 & 0.063477 \\
-1.628770 & 0.002718 & 0.004722 & -0.023100 \\
-0.166929 & 1.076946 & 0.190533 & 0.146018 \\
0.067651 & 0.025108 & -0.139675 & -0.031818 \\
0.227011 & 0.015675 & 0.001580 & -0.091496 \\
0.000000 & 0.000000 & 0.000000 & 0.000000 \\
0.000000 & 0.000000 & 0.000000 & 0.000000 \\
0.000000 & 0.000000 & 0.000000 & 0.000000
\end{array}\right],
\end{array} \\
& \begin{array}{c}
\mathbf{A}_{H}=\left[\begin{array}{llll}
\mathbf{A}_{H 1} & \mathbf{A}_{H 2}
\end{array}\right], \\
\mathbf{B}_{H 1}=\left[\begin{array}{cccc}
0.112449 & -0.019934 & 0.191121 & -0.000000 \\
-0.033941 & 0.197670 & 0.022143 & 0.063477 \\
-1.628770 & 0.002718 & 0.004722 & -0.023100 \\
-0.166929 & 1.076946 & 0.190533 & 0.146018 \\
0.067651 & 0.025108 & -0.139675 & -0.031818 \\
0.227011 & 0.015675 & 0.001580 & -0.091496 \\
0.000000 & 0.000000 & 0.000000 & 0.000000 \\
0.000000 & 0.000000 & 0.000000 & 0.000000 \\
0.000000 & 0.000000 & 0.000000 & 0.000000
\end{array}\right],
\end{array}
\end{aligned}
$$

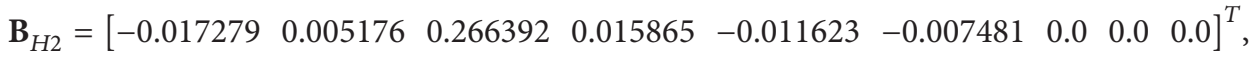

$$
\begin{aligned}
& \mathbf{C}_{H}=\left[\begin{array}{lllllllll}
1 & 0 & 0 & 0 & 0 & 0 & 0 & 0 & 0 \\
0 & 1 & 0 & 0 & 0 & 0 & 0 & 0 & 0 \\
0 & 0 & 1 & 0 & 0 & 0 & 0 & 1 & 0
\end{array}\right], \quad \mathbf{D}_{H 1}=\mathbf{O}_{3 \times 3}, \quad \mathbf{D}_{H 11}=\mathbf{O}_{3 \times 1}
\end{aligned}
$$




$$
\begin{gathered}
\Lambda=\operatorname{diag}\left(\left[\begin{array}{llllllllllllll}
1.0 & 1.0 & 1.0 & 1.0 & 1.0 & 1.0 & 1.0 & 1.0 & 1.0 & 0.9 & 0.9 & 0.9 & 1.5
\end{array}\right]\right), \\
\mathbf{R}=\operatorname{diag}\left(\left[\begin{array}{llllll}
1.0 & 1.0 & 1.0 & 1.5
\end{array}\right]\right)
\end{gathered}
$$

And the scalar $\gamma_{1}=40$.

Using the method described in Section 3.1, the controller gains are solved as follows:

$$
\begin{gathered}
\mathbf{K}_{H x}=\left[\begin{array}{ccccccccc}
-0.4504 & -0.0772 & -1.0713 & -0.0865 & 0.7182 & 1.9362 & -1.1411 & 1.7660 & 6.5718 \\
-0.5341 & 2.2872 & 0.1233 & 2.5210 & 2.1920 & 2.4541 & 27.8091 & 1.1174 & 7.7398 \\
2.9540 & 0.3435 & 0.0242 & 0.3770 & -12.6501 & 1.8986 & 4.8150 & 0.7553 & -42.5235 \\
0.2852 & 0.1526 & -0.8469 & 0.2251 & -0.8352 & -6.3462 & 1.1669 & -4.0489 & -4.0343
\end{array}\right], \\
\mathbf{K}_{H e}=\left[\begin{array}{ccccc}
0.1086 & 0.0488 & 0.8277 & -0.5784 \\
0.1567 & -0.9179 & -0.0592 & -0.2213 \\
-0.9243 & -0.1294 & 0.0392 & -0.2139 \\
-0.0790 & -0.1598 & 0.3741 & 0.8449
\end{array}\right]
\end{gathered}
$$

Thus, the out layer control law for the integrated helicopter and engine system is expressed as

$$
\mathbf{U}_{H}=\mathbf{K}_{H x} \mathbf{x}_{H}+\mathbf{K}_{H e} \int_{0}^{\mathbf{t}} \mathbf{e}_{H} \mathbf{d} \boldsymbol{\tau}
$$

3.4. Design for Inner Loop Control in Emergency Flight. For the integrated helicopter and engine system, the system state, control input, and system output are introduced, respectively, as follows:

$$
\begin{aligned}
& \text { state vector is } \mathbf{x}_{E}=\left[\begin{array}{lll}
V_{z} & N_{p} & N_{g}
\end{array}\right]^{T}, \\
& \text { control input vector is } \mathbf{U}_{E}=\left[\begin{array}{lll}
\theta_{0}^{\prime} & W_{f} & W_{g_{\text {out }}}
\end{array}\right]^{T,} \\
& \text { output vector is } \mathbf{y}_{E}=\left[\begin{array}{lll}
V_{z} & N_{p} & N_{g}
\end{array}\right]^{T}, \\
& \text { command signal is } \mathbf{c m d}_{E}=\left[\begin{array}{lll}
V_{z \mathrm{cmd}} & N_{p \mathrm{cmd}} & N_{g \mathrm{cmd}}
\end{array}\right]^{T}, \\
& \text { output error vector is } \mathbf{e}_{E}=\mathbf{c m d}_{E}-\mathbf{y}_{E}, \\
& \text { disturbance is } w=Q_{H} .
\end{aligned}
$$

In the relative engine state $\left(N_{p}=100 \%, N_{g}=88.6 \%\right)$ for the above hover state, system matrices can also be fitted by small perturbation method [30] as

$$
\begin{aligned}
\mathbf{A}_{E} & =\left[\begin{array}{ccc}
-0.239124 & -0.254130 & -0.270133 \\
2.691120 & -0.165848 & -0.468932 \\
-0.012819 & -0.002656 & -1.693173
\end{array}\right], \\
\mathbf{B}_{E 1} & =\left[\begin{array}{lll}
-0.256693 & -0.016399 & -0.038242 \\
-0.228991 & -0.546528 & -0.492449 \\
-0.001338 & -0.269171 & -0.107159
\end{array}\right],
\end{aligned}
$$

$$
\begin{gathered}
\mathbf{B}_{E 2}=\left[\begin{array}{lll}
-0.017279 & -0.011623 & -0.007481
\end{array}\right]^{T}, \\
\mathbf{C}_{E}=\mathbf{I}_{3 \times 3}, \quad \mathbf{D}_{E 1}=\mathbf{O}_{3 \times 3}, \quad \mathbf{D}_{E 11}=\mathbf{O}_{3 \times 1} .
\end{gathered}
$$

By trial and error, the weighted matrices are chosen as

$$
\begin{gathered}
\mathbf{\Lambda}=\operatorname{diag}\left(\left[\begin{array}{llllll}
1.0 & 0.9 & 0.76 & 0.8 & 0.45 & 0.76
\end{array}\right]\right) \\
\mathbf{R}=\operatorname{diag}\left(\left[\begin{array}{lll}
1.1 & 0.9 & 1.2
\end{array}\right]\right)
\end{gathered}
$$

And the scalar $\gamma_{1}=40$.

Also, using the design method described in Section 3.1, we can acquire the following controller gains:

$$
\begin{aligned}
& \mathbf{K}_{E e}=\left[\begin{array}{ccc}
0.7257 & 0.6687 & -0.1614 \\
0.3082 & -0.5263 & -0.7918 \\
-0.6150 & 0.5253 & -0.5880
\end{array}\right], \\
& \mathbf{K}_{E x}=\left[\begin{array}{ccc}
-2.6069 & -0.5658 & -0.0655 \\
0.7030 & 0.8282 & 0.3956 \\
-0.5780 & -0.9703 & 0.5477
\end{array}\right] .
\end{aligned}
$$

Thus, the inner controller for the integrated helicopter and engine system is expressed as

$$
\mathbf{U}_{E}=\mathbf{K}_{E x} \mathbf{x}_{E}+\mathbf{K}_{E e} \int_{0}^{\mathbf{t}} \mathbf{e}_{E} \mathbf{d} \boldsymbol{\tau}
$$

3.5. Two-Layer Control Law for Integrated UH-60/T700 Engine System. Based on the description in Section 3.2, 


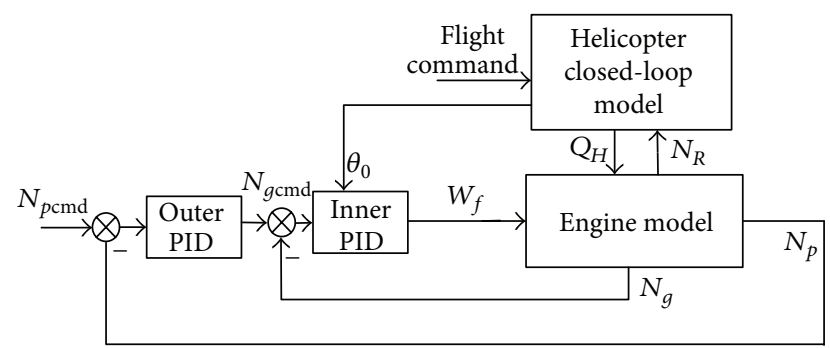

Figure 4: Cascade PID control for engines.

the two-layer control law for the integrated UH-60/T700 engine system is followed by

$$
\begin{gathered}
\mathbf{U}_{H}=\left[\begin{array}{l}
u_{E 1} \\
u_{H 2} \\
u_{H 3} \\
u_{H 4}
\end{array}\right]=\left[\begin{array}{c}
\theta_{0}^{\prime} \\
A_{1 s} \\
B_{1 c} \\
\theta_{t}
\end{array}\right], \\
\mathbf{U}_{E}=\left[\begin{array}{l}
u_{E 2} \\
u_{E 3}
\end{array}\right]=\left[\begin{array}{c}
W_{f} \\
W_{g_{\text {out }}}
\end{array}\right] .
\end{gathered}
$$

\section{Validations and Discussions}

To validate the feasibility of the proposed control law, some rapid ascent and descent flight tasks are simulated and compared with the conventional cascade PID control. For simplicity, the novel two-layer emergent integrated system control is labeled in short as TLESC here. Figure 4 depicts the block diagram of the conventional PID method.

The cascade PID control law is formulated as

$$
\begin{gathered}
W_{f}=k_{p 2} e_{2}+k_{i 2} \int_{0}^{t} e_{2} d t+k_{\theta_{0}} \frac{d \theta_{0}}{d t}, \\
e_{1}=N_{p \mathrm{cmd}}-N_{p}, \quad e_{2}=N_{g \mathrm{cmd}}-N_{g}, \\
N_{g \mathrm{cmd}}=k_{p 1} e_{1}+k_{d 1} \frac{d e_{1}}{d t},
\end{gathered}
$$

where $k_{p 1}, k_{i 1}$ are the relative parameters for outer loop, $k_{p 2}, k_{i 2}$ are the parameters for inner loop, $e_{1}, e_{2}$ are denoted as errors for the two feedback loops, and $K_{\theta_{0}}$ is collective feed forward gain. And all the parameters for the PID control are well modulated and verified over the entire envelope.

Two testing cases are demonstrated as follows.

4.1. The First Testing Case. In this simulation case, the helicopter is initialed from a hover state with a low height $H=100 \mathrm{~m}$ and low forward velocity $V_{x}=8 \mathrm{~m} / \mathrm{s}$, and the relative engine states are power turbine speed $N_{p}=100 \%$ and gas turbine speed $N_{g}=87.88 \%$. At $t=0 \mathrm{sec}$, a rapid climbing task (or bop up) began, and the command signals for the inner layer are preset as $V_{z \mathrm{cmd}}=4 \mathrm{~m} / \mathrm{s}$, $N_{p c m d}=100 \%$, and $N_{g c m d}=92.88 \%$. For the purpose of clarifying more clearly, all the parameters related to inner layer control are presented as deviations using a notation $\delta$. Then, conditions in Theorem 1 should be firstly checked. For inner layer or engine control, the parameters in condition (A) are modulated as $\gamma_{E}=0.25, q_{E}=2$. Next, condition (B) is easily qualified by the above control law, and $M_{E}=1, \lambda_{E}=$ $\lambda_{\text {min }}\left(\overline{\mathbf{A}}_{E}+\overline{\mathbf{B}}_{E} \overline{\mathbf{K}}_{E}\right)=-1.7257$ would be gotten based on the formulation $\left\|e^{\overline{\mathbf{A}}_{E}+\overline{\mathbf{B}}_{E} \overline{\mathbf{K}}_{E}}\right\|<M_{E} e^{\lambda_{E} t}$. There upon for initial condition can be quantified as follows:

$$
\left\|\overline{\mathbf{x}}_{0}\right\|<\frac{\left|\lambda_{E}\right|}{\gamma_{E} M_{E}^{q_{E}}}=\frac{1.72}{0.25}=6.88 .
$$

Figures 5(a), 5(b), and 5(c) depict that the tracking responses of the three channels of ascending velocity $V_{z}$, power turbine speed $N_{p}$, and gas turbine speed $N_{g}$, and the initial states for them satisfy the formulation $\left\|\overline{\mathbf{x}}_{0}\right\|^{q_{E}-1}<$ $\left|\lambda_{E}\right| / \gamma_{E} M_{E}{ }^{q_{E}}$. So conditions of Theorem 1 for this case are fulfilled. Time histories of control inputs are displayed in Figures 5(d), 5(e), and 5(f), respectively, which are rotor collective angle $\theta_{0}$, fuel flow $W_{f}$, and turbine bleeding gas flow $W_{\text {gout }}$. As can be seen clearly from these figures, when the proposed method is utilized to execute the flight task, it takes about 2.0 seconds for the helicopter to track the command signals asymptotically. Otherwise when using the PID method, the transient time of this process is about 10.0 seconds. Therefore, the TLESC enhances greatly the dynamic performance in the climbing task and significantly reduces the tracking time. Figures $5(\mathrm{~g}), 5(\mathrm{~h})$, and $5(\mathrm{i})$ give the time histories of power supplying to helicopter $H_{P P}$, total temperature of gas turbine outlet $T_{45}$, and stall margin of compressor $\mathrm{SM}_{C} . H_{P P}$ changes are explanations for the convergent time to track command signals, and faster $H_{P P}$ changes means faster response to helicopter flight variations. In the transient process, the gas turbine outlet temperature (less than $1000 \mathrm{~K}$ ) and stall margin (more than 10\%) are both in permit ranges. In Figure $5(\mathrm{~g})$, it is shown that turbine bleeding can significantly influence the change rate of output power and bring a rapid change of $T_{45}$ (see Figure 5(h)). Furthermore, an interesting phenomenon can be observed in Figure 5(i); that is, when using this new method $\mathrm{SM}_{C}$ has an increasing trend in the whole process due to a reduction of total pressure in gas turbine outlet. Obviously, Figure 5(b) indicates that when the TLESC law is used, not only is the response time significantly reduced but also the $N_{p}$ variation in transient process is reduced from $1.87 \%$ under PID to $0.46 \%$. Therefore the antidisturbance capability of closedloop system is much more improved by the TLESC law. For the out layer or flight control, the simulation results are also provided here.

Similarly, for out layer or flight control the parameters in condition $(\mathrm{A})$ are modulated as $\gamma_{H}=0.9, q_{H}=2$. Next, $M_{H}=$ $1, \lambda_{H}=\lambda_{\text {min }}\left(\overline{\mathbf{A}}_{H}+\overline{\mathbf{B}}_{H} \overline{\mathbf{K}}_{H}\right)=-4.4776$ would be acquired based on the formulation $\| e^{\overline{\mathbf{A}}+\overline{\mathbf{B K}}_{\|}}<M e^{\lambda t}$. Thus, the initial state condition of $\left\|\overline{\mathbf{x}}_{0}\right\|^{q_{H}-1}<\left|\lambda_{H}\right| / \gamma_{H} M_{H}{ }^{q_{H}}$ can be quantified as follows:

$$
\left\|\overline{\mathbf{x}}_{0}\right\|<\frac{\left|\lambda_{H}\right|}{\gamma_{H} M_{H}^{q_{H}}}=\frac{4.4776}{0.9}=4.975 .
$$

Figures 5(k), 5(l), 5(m), 5(n), and 5(o) depict time changes of forward flight velocity $V_{x}$, sideward flight velocity $V_{y}$, yaw angle $\psi$, lateral cyclic pitch $A_{1 c}$, longitudinal cyclic pitch $B_{1 s}$ 


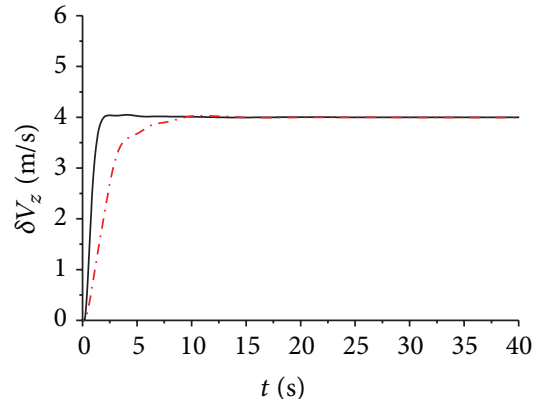

$-\delta V_{z}$-TLESC

-.. $\delta V_{z}$-PID

(a) Time responses of tracking $V_{z \mathrm{cmd}}$

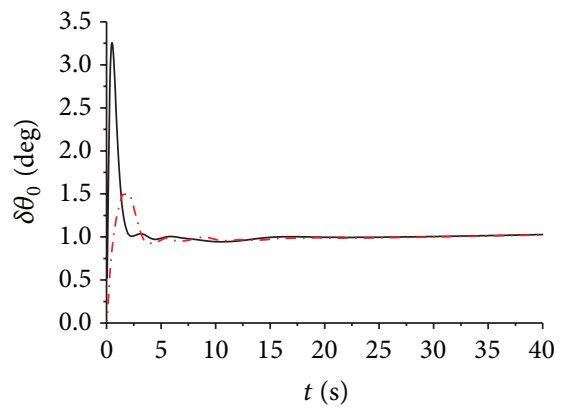

$-\delta \theta_{0}$-TLESC

$\cdots \delta \theta_{0}$-PID

(d) Time histories of $\theta_{0}$

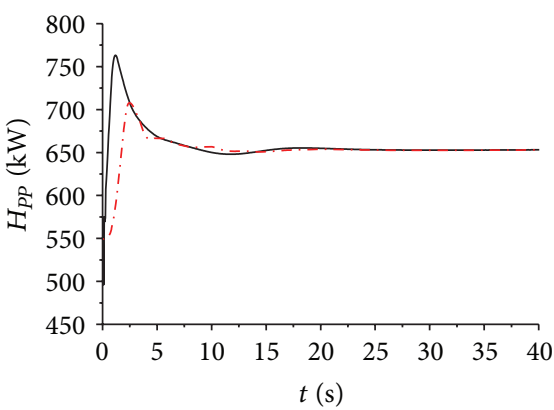

$-H_{P P^{-T L E S C}}$

-. - $H_{P P}$-PID

(g) Time histories of $H_{P P}$

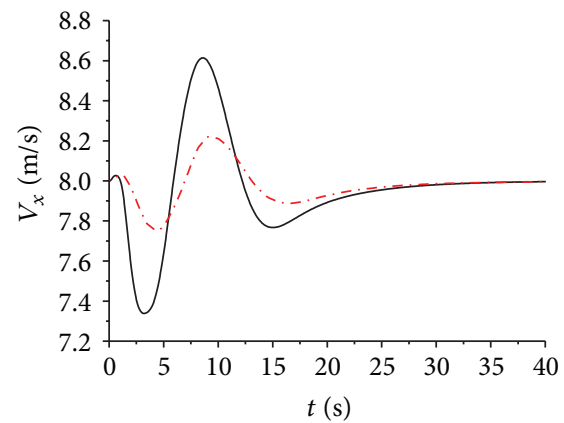

- $V_{x}$-TLESC

-. $V_{x}$-PID

(j) Time histories of $V_{x}$

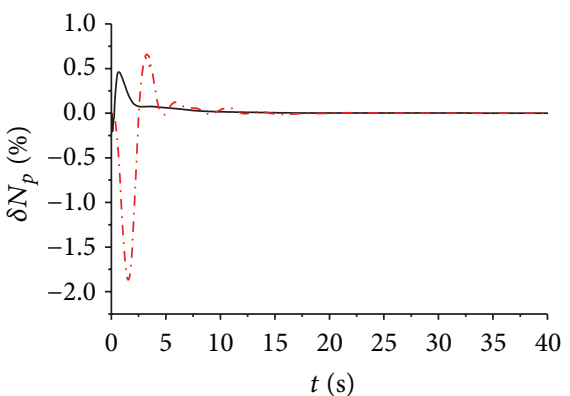

$\delta N_{p}$-TLESC

(b) Time responses of tracking $N_{p c m d}$

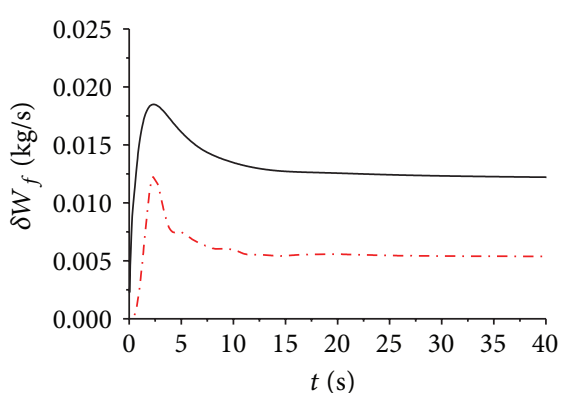

$-\delta W_{f}$-TLESC

-.- $\delta W_{f}$-PID

(e) Time histories of $W_{f}$

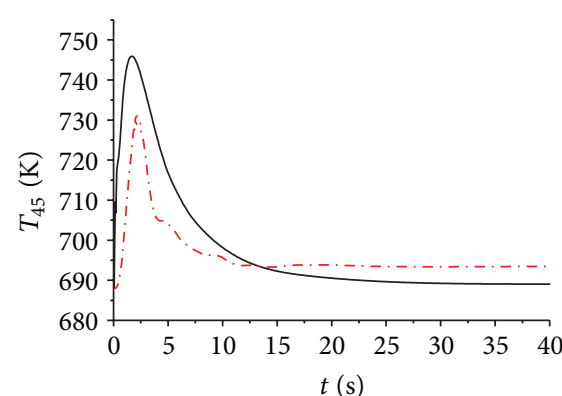

- $T_{45}$-TLESC

-.. $T_{45}$-PID

(h) Time histories of $T_{45}$

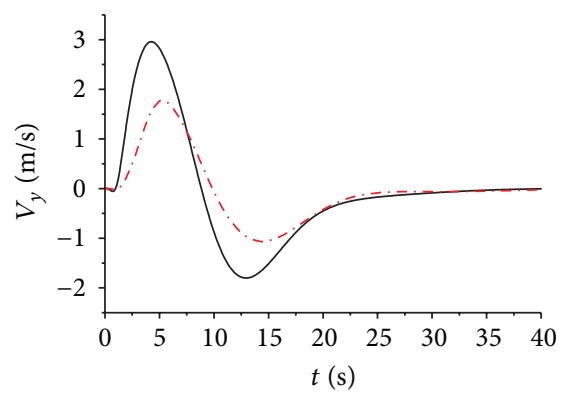

$-V_{y}$-TLESC

$\cdot-\cdot V_{y}$-PID

(k) Time histories of $V_{y}$

Figure 5: Continued.

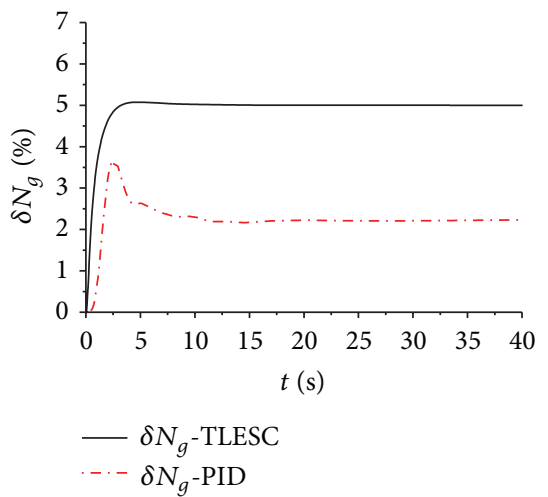

(c) Time responses of tracking $N_{g c m d}$

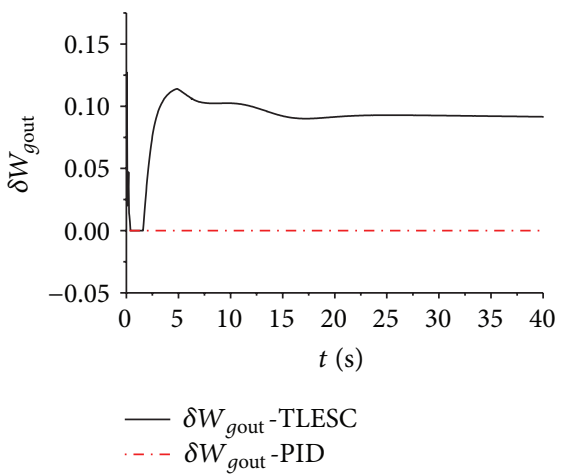

(f) Time histories of $W_{\text {gout }}$

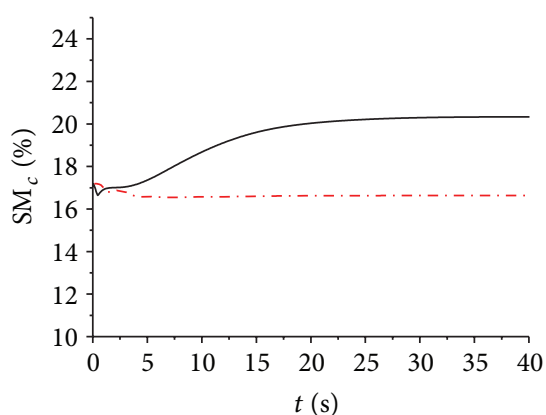

$\mathrm{SM}_{c}$-TLESC

..- $\mathrm{SM}_{c}$-PID

(i) Time histories of $\mathrm{SM}_{C}$

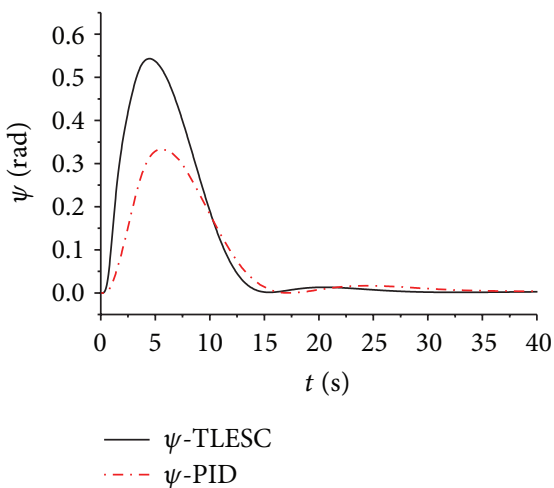

(l) Time histories of $\psi$ 


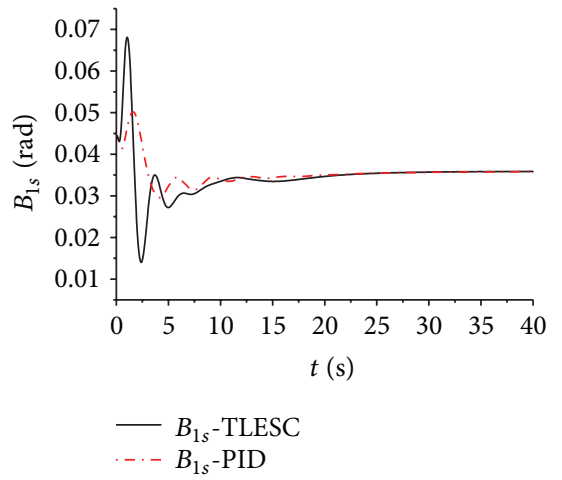

(m) Time histories of $B_{1 s}$

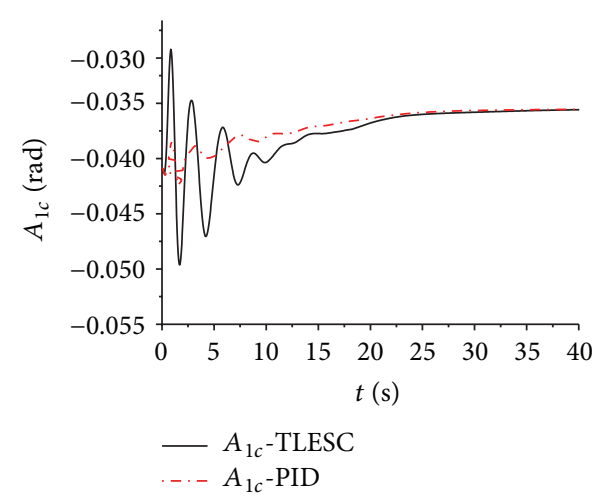

(n) Time histories of $A_{1 c}$

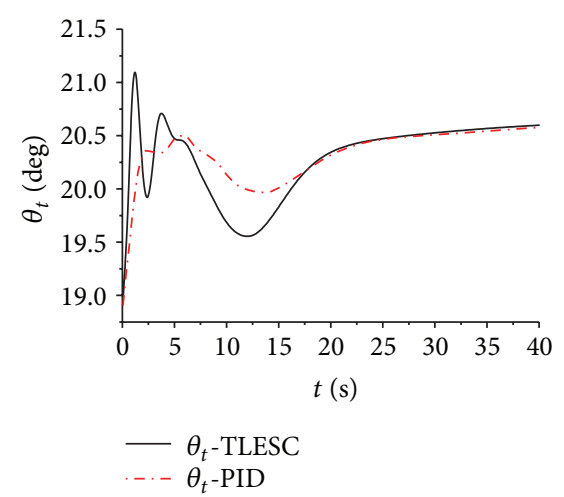

(o) Time histories of $\theta_{t}$

FIGURE 5: Simulation results for helicopter rapid climbing.

and tail rotor collective angle $\theta_{t}$. It can be found that all the states of flight control are within the range of $\left\|\overline{\mathbf{x}}_{0}\right\|<4.975$.

4.2. The Second Case. In order to verify the robustness of this new TLESC method over the entire envelope, another rapid descent flight demonstration (Figure 6) is also conducted, which is triggered from a hover state of $H=400 \mathrm{~m}, V_{x}=$ $45 \mathrm{~m} / \mathrm{s}$, and $V_{z}=0 \mathrm{~m} / \mathrm{s}$, and the relative engine states are $N_{g}=82.17 \%$ and $N_{p}=100 \%$. Depicted in Figure 6, when at $t=0 \mathrm{~s}$ the command signals are preset as $V_{z \mathrm{cmd}}=-3 \mathrm{~m} / \mathrm{s}$, $N_{p \mathrm{cmd}}=100 \%$, and $N_{g \mathrm{cmd}}=80.17 \%$.

The tracking responses of $V_{z}, N_{g}$, and $N_{p}$ are shown in Figures 6(a), 6(b), and 6(c), whereas the time histories of control variables are demonstrated in Figures 6(d), 6(e), and 6(f), respectively. As can be seen clearly from these results, for the closed-loop system based on the new control law, the convergent time for tracking $V_{z \mathrm{cmd}}$ is about 1.6 seconds. On the contrary, when using the conventional PID control, the tracking time is about 18.2 seconds, much slower than the previous one. Thus the closed system constructed by TLESC control has better asymptotically tracking performance. Moreover, Figure 6(b) shows a slight smaller droop of $N_{p}$ under the TLESC method than PID. Furthermore, as can be seen from Figure 6(g), the TLESC control is capable of regulating output power more rapidly, which enhances the engine response to helicopter. Figure 6(i) presents a similar increasing trend in $\mathrm{SM}_{C}$ as happened in the first simulation case, and the mechanism is the same as analyzed in Figure 6. For the out layer or flight control loops, the simulation results are also provided.

4.3. Discussions. Turbine bleeding is added as an extra control parameter in the new control scheme; thereby it has the potential to regulate output power of engine in mechanism. Next, by the aid of the proposed control method, the TLESC method, incorporating with turbine bleeding, fuel flow, and rotor collective control, is developed to reach the control object of faster response for engines.

Of course, this rapid control for power demand also brings some negative effects especially in other flight channels. As discussed in Section 3.2, the two-layer control significantly reduces the response time in vertical channel, while it also adds extra disturbance to other flight channels as shown in Figures 5 and 6. Nevertheless, the most significant consideration in emergency state is the rapid escaping motion, when the helicopter is close to or fleeing away some obstacle in vertical orientation. Hence, the negative influence can be omitted to a great extent due to the profit in response time.

\section{Conclusions}

A two-layer robust control law, augmented by turbine bleeding, is proposed to implement a feasible emergency state control for an integrated helicopter flight/engine system. Based on the integrated Hawk helicopter/T700 engines model, necessary applications are provided for the integrated system undergoing rapid climbing and decent tasks, in order to verify the feasibility and robustness of this new control method for nonlinear plants. Moreover, the simulation results are compared to conventional control laws. Simulation results show that the closed-loop system, designed by this proposed control law, has better dynamic and static performance in wider envelope and can asymptotically track the command signals more rapidly.

\section{Nomenclature}

\begin{tabular}{|c|c|}
\hline$W_{f}:$ & Main fuel flow $(\mathrm{kg} / \mathrm{s})$ \\
\hline$X_{\mathrm{SUM}}, Y_{\mathrm{SUM}}, Z_{\mathrm{SUM}}:$ & $\begin{array}{l}\text { Summed forces for all components } \\
\text { of helicopter with respect to }\end{array}$ \\
\hline & A-Frame $(\mathrm{N})$ \\
\hline$W_{g_{\text {out }}}$ & Turbine bleeding gas flow ratio (-) \\
\hline$L_{\mathrm{SUM}}, M_{\mathrm{SUM}}, N_{\mathrm{SUM}}:$ & $\begin{array}{l}\text { Summed moments for all } \\
\text { components of helicopter with } \\
\text { respect to A-Frame }(\mathrm{N} \cdot \mathrm{m})\end{array}$ \\
\hline$N_{g}, N_{p}, N_{R}$ & $\begin{array}{l}\text { Revolution speed of gas turbine, } \\
\text { power turbine, and rotor ( } \mathrm{r} / \mathrm{min} \text { or } \\
\% \text { for simplicity) }\end{array}$ \\
\hline$I_{X}, I_{Y}, I_{Z}$ & $\begin{array}{l}\text { Moment of inertia about } X, Y \text {, and } Z \\
\text { axis with respect to A-Frame }\left(\mathrm{kg} \cdot \mathrm{m}^{2}\right)\end{array}$ \\
\hline
\end{tabular}




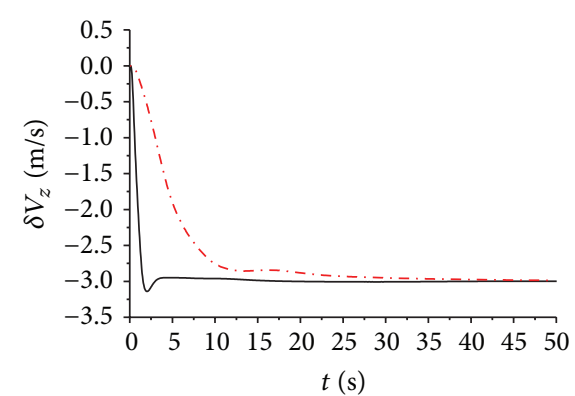

$-\delta V_{z}$-TLESC

-.- $\delta V_{z}$-PID

(a) Time responses of tracking $V_{z \mathrm{cmd}}$

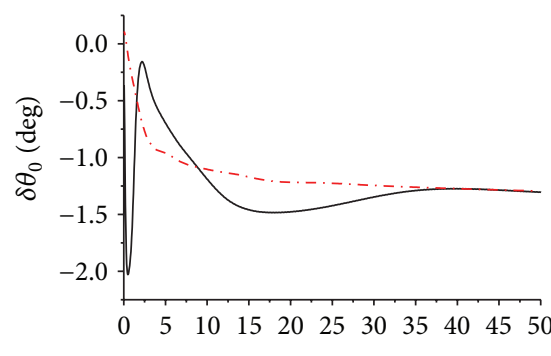

$t(\mathrm{~s})$

$-\delta \theta_{0}$-TLESC

- - $\delta \theta_{0}$-PID

(d) Time changes of $\theta_{0}$

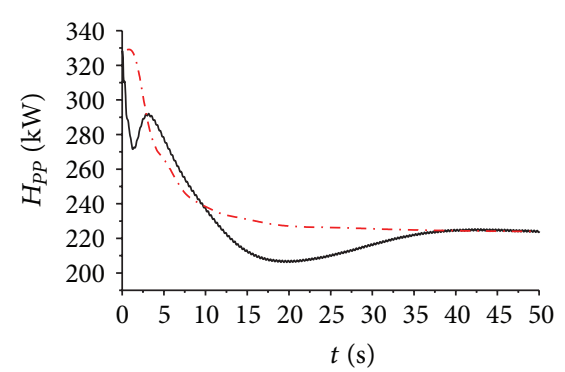

$-H_{P P}$-TLESC

-..- $H_{P P}$-PID

(g) Time changes of $H_{P P}$

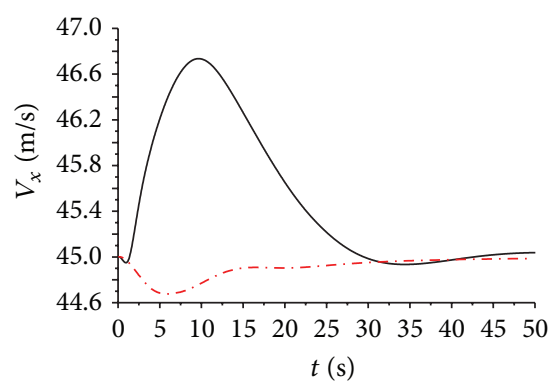

$V_{x}$-TLESC

-. - $V_{x}$-PID

(j) Time changes of $V_{x}$

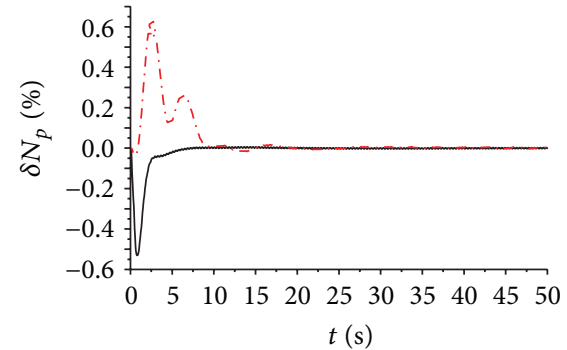

$\delta N_{p}$-TLESC

$\delta N_{p}$-PID

(b) Time responses of tracking $N_{p c m d}$

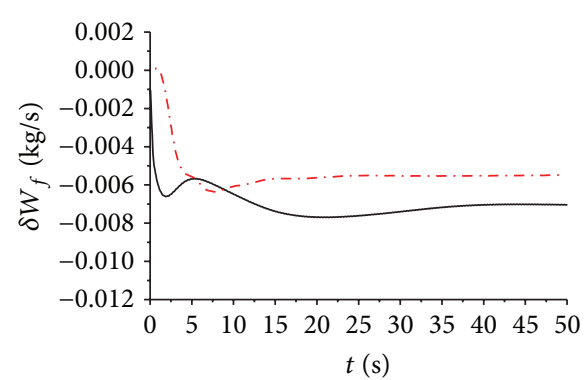

$-\delta W_{f}$-TLESC

-.- $\delta W_{f}$-PID

(e) Time changes of $W_{f}$

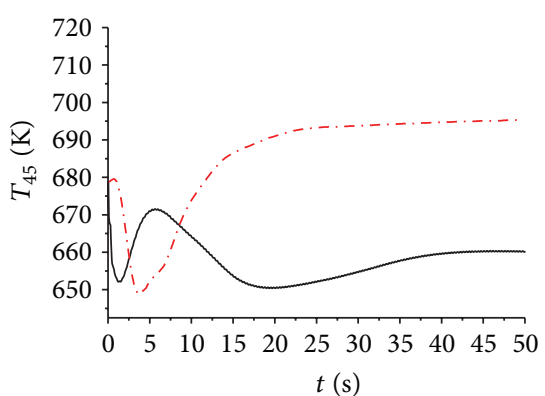

- $T_{45}$-TLESC

...- $T_{45}$-PID

(h) Time changes of $T_{45}$

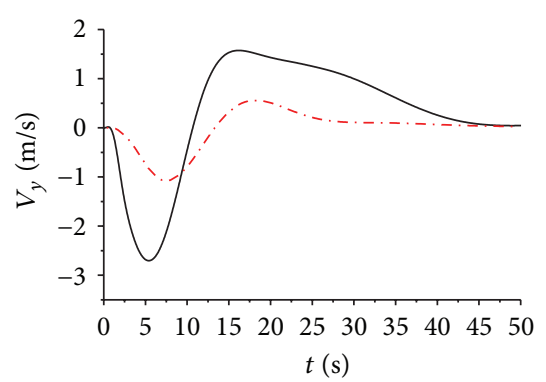

$-V_{y}$-TLESC
$--V_{y}$-PID

(k) Time changes of $V_{y}$

Figure 6: Continued.

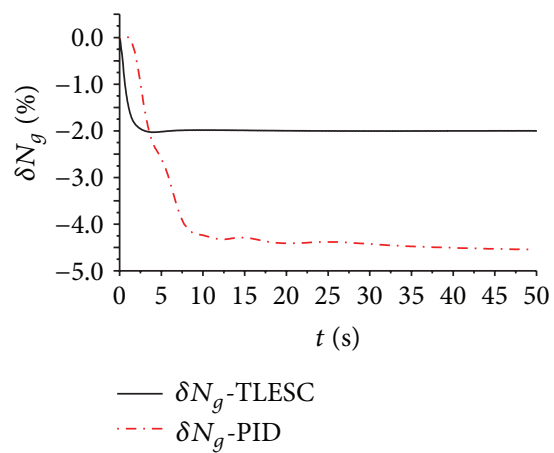

(c) Time responses of tracking $N_{g c m d}$

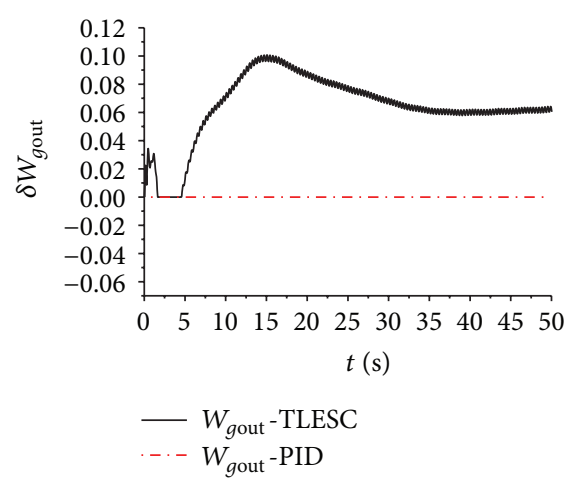

(f) Time changes of $W_{\text {gout }}$

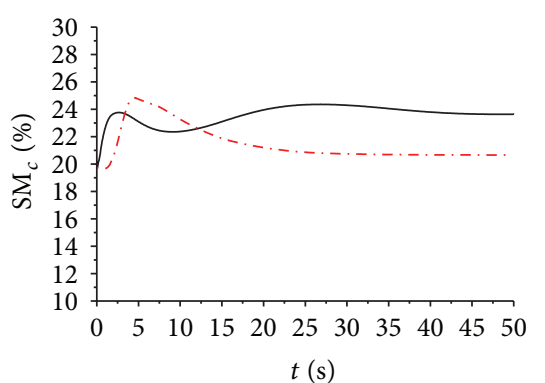

- $\mathrm{SM}_{c}$-TLESC

-. $\mathrm{SM}_{c}$-PID

(i) Time changes of $\mathrm{SM}_{C}$

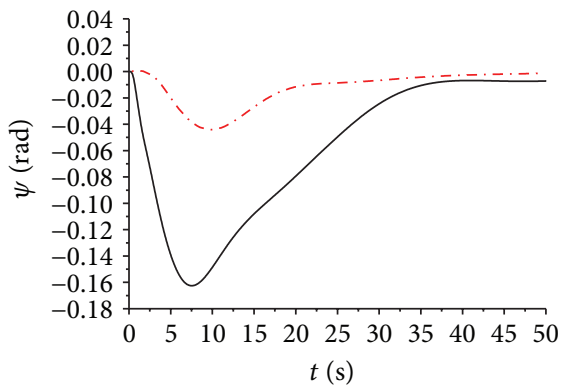

$-\psi$-TLESC
.$--\psi$-PID

(l) Time changes of $\psi$ 


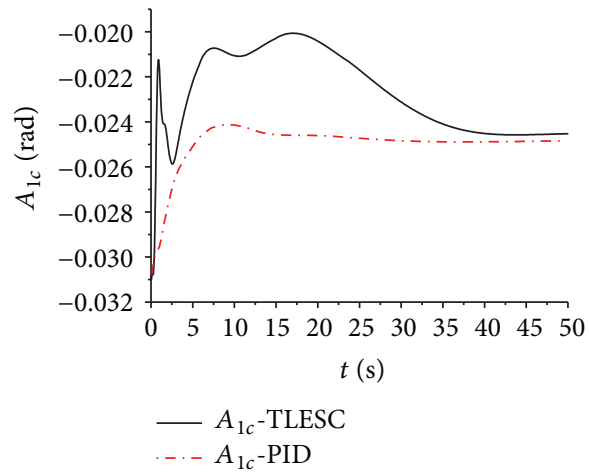

(m) Time changes of $A_{1 c}$

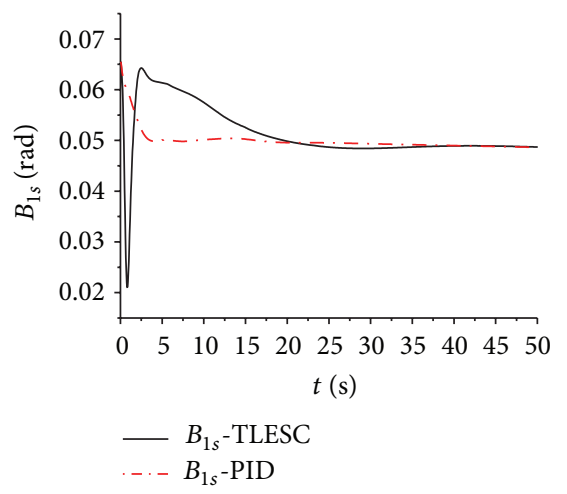

(n) Time changes of $B_{1 s}$

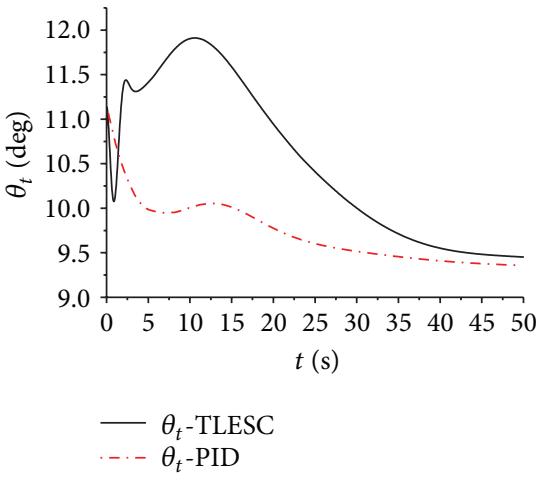

(o) Time changes of $\theta_{t}$

FIGURE 6: Simulation results for helicopter rapid decent.

\begin{tabular}{|c|c|}
\hline$P_{44}, P_{45}, P_{5}:$ & $\begin{array}{l}\text { total pressure of gas turbine } \\
\text { outlet, power turbine outlet, } \\
\text { and nozzle outlet }(\mathrm{Pa})\end{array}$ \\
\hline$I_{x Z}:$ & $\begin{array}{l}\text { Moment of inertia product } \\
\text { about the crossing axis with } \\
\text { respect to A-Frame }\left(\mathrm{kg} \cdot \mathrm{m}^{2}\right)\end{array}$ \\
\hline$V_{g}, V_{p} V_{\mathrm{nz}}:$ & $\begin{array}{l}\text { typical volumes of gas tur- } \\
\text { bine, power turbine, and noz- } \\
\text { zle }\left(\mathrm{m}^{3}\right)\end{array}$ \\
\hline G: & weight of helicopter $(\mathrm{N})$ \\
\hline$T_{44}, T_{45}, T_{5}$ & $\begin{array}{l}\text { Gas total temperature in gas } \\
\text { turbine outlet, power turbine } \\
\text { outlet, and nozzle outlet }(\mathrm{K})\end{array}$ \\
\hline$g:$ & gravity constant $\left(9.8 \mathrm{~m} / \mathrm{s}^{2}\right)$ \\
\hline$P W_{\text {out }}, P W_{p}, P W_{g}, P W_{c}:$ & $\begin{array}{l}\text { Power needed by helicopter, } \\
\text { power supplied from power } \\
\text { turbine, power supplied from } \\
\text { gas turbine, and that needed } \\
\text { for compressor }(\mathrm{kw})\end{array}$ \\
\hline$\Psi, \phi, \Theta:$ & $\begin{array}{l}\text { Yaw angle, roll angle, and pitch } \\
\text { angle of helicopter }\left(^{\circ}\right)\end{array}$ \\
\hline$m_{g 44}, m_{g 45}, m_{g 5}, m_{a 3}:$ & $\begin{array}{l}\text { Gas flow in gas turbine outlet, } \\
\text { power turbine outlet, nozzle } \\
\text { outlet, and compressor outlet } \\
\text { air flow }(\mathrm{kg} / \mathrm{s})\end{array}$ \\
\hline$\theta_{0}, A_{1 c}, B_{1 s}, \theta_{t}$ & $\begin{array}{l}\text { Rotor collective angle, lateral } \\
\text { cyclic pitch, and longitudinal } \\
\text { cyclic pitch }\left(^{\circ}\right)\end{array}$ \\
\hline$H:$ & Flight altitude \\
\hline$J_{R}:$ & $\begin{array}{l}\text { Moment of inertia of rotor } \\
\left(\mathrm{kg} \cdot \mathrm{m}^{2}\right)\end{array}$ \\
\hline$J_{p}, J_{g}:$ & $\begin{array}{l}\text { Power turbine moment of ini- } \\
\text { tial, power turbine moment of } \\
\text { initial }\left(\mathrm{kg} \cdot \mathrm{m}^{2}\right)\end{array}$ \\
\hline$J_{\mathrm{GB}}:$ & $\begin{array}{l}\text { Moment of inertia of gearbox } \\
\left(\mathrm{kg} \cdot \mathrm{m}^{2}\right)\end{array}$ \\
\hline $\mathrm{SM}_{C}:$ & Stall margin of compressor \\
\hline$J_{\mathrm{TL}}:$ & $\begin{array}{l}\text { Moment of inertia of tail rot } \\
\left(\mathrm{kg} \cdot \mathrm{m}^{2}\right)\end{array}$ \\
\hline O. & $\begin{array}{l}\text { Output torque of power tur- } \\
\text { bine }(\mathrm{N} \cdot \mathrm{m})\end{array}$ \\
\hline
\end{tabular}

$J_{E}:$

$Q_{H}$ :

$J_{\text {acc }}$ :

E-Frame:

$\Omega_{R}$ :

$X_{E}, Y_{E}, Z_{E}$ :

$\Omega_{E}$ :

A-Frame:

$\Omega_{\mathrm{GB}}$ :

$X, Y, Z$ :

$\Omega_{\mathrm{TR}}$ :

H-Frame:

Cmd:

$X_{H}, Y_{H}, Z_{H}$ :

Subscript $H$ :

$V_{x}, V_{y}, V_{z}$ :

Subscript E:

$u, v, w$ :

Subscript 1, 2, 3, 4, 44, 45, 5: engine inlet, compressor inlet, combustion chamber inlet, gas turbine inlet, gas turbine outlet, power turbine outlet, and exhaust nozzle outlet

$p, q, r:$ Angular rate about $X$-axis, $Y$ axis, and $Z$-axis with respect to A-Frame ( $\mathrm{rad} / \mathrm{s})$.

\section{Conflict of Interests}

The authors declare no conflict of interests. 


\section{Acknowledgments}

The work has been supported by the NUAA Fundamental Research Funds, no. NS2013021. The authors are also grateful to give thanks to China Scholarship Council for its financial support.

\section{References}

[1] S. Garg, P. J. Ouzts, C. F. Lorenzo, and D. L. Mattern, "IMPACan integrated methodology for propulsion and airframe control," in Proceedings of the American Control Conference, pp. 747754, Boston, Mass, USA, June 1991.

[2] S. Garg and D. L. Mattern, "Application of an integrated methodology for propulsion and airframe control design to a STOVL aircraft," in Proceedings of the Guidance, Navigation and Control Conference, 1994, AIAA paper no. 94-3611-CP.

[3] S. Garg, "Partitioning of centralized integrated flight/propulsion control design for decentralized implementation," IEEE Transactions on Control Systems Technology, vol. 1, no. 2, pp. 93100, 1993.

[4] N. Gibson, "Intelligent engine systems: adaptive control," Tech. Rep. NASA/CR-2008-215240, NASA, 2008.

[5] S. Garg, "Introduction to advanced engine control concepts," Tech. Rep. 20070010763, NASA, 2007.

[6] B. J. Smith and R. D. Zagranski, "Next generation control system for helicopter engines," in Proceedings of the 57th AHS International Annual Forum, 2001.

[7] B. J. Smith and R. D. Zagranski, "Closed loop bench testing of the next generation control system for helicopter engines," in Proceedings of the 58th AHS International Annual Forum, pp. 1041-1050, Montreal, Canada, 2002.

[8] J. S. Litt, J. M. Edwards, and J. A. DeCastro, "A sequential shifting algorithm for variable rotor speed control," Tech. Rep. NASA/TM-2007-214842, 2007.

[9] W. Guo and J. F. Horn, "Rotor state feedback control for rotorcraft with variable rotor speed," in Proceedings of the AIAA Guidance, Navigation, and Control Conference and Exhibit, August 2009, AIAA paper no. 2009-5797.

[10] T. Iwata and S. M. Rock, "Benefits of variable rotor speed in integrated helicopter/engine control," in Proceedings of the AIAA Guidance, Navigation and Control Conference, 1993, AIAA paper no. 93-3851-CP.

[11] J. S. Litt, D. K. Frederick, and T. H. Guo, "The case for intelligent propulsion control for fast engine response," Tech. Rep. NASA/TM-2009-215668, Glenn Research Center, Cleveland, Ohio, USA, 2009.

[12] J. S. Litt and T.-H. Guo, "Fast thrust response for improved flight/propulsion system simulation of a large commercail aircraft engine," in Proceedings of the AIAA Guidance, Navigation and Control Conference and Exhibit, August 2008.

[13] T. H. Guo, J. S. Litt, W. Merrill, and B. Wood, "Fast-response research: IRAC propusion task," in Proceedings of the NASA Aviation Safty Technical Conference, 2008.

[14] L. C. Jaw and J. D. Mattingly, Aircraft Engine Controls Design, System Analysis, and Health Monitoring, American Institute of Aeronautics and Astronautics, Reston, Va, USA, 2009.

[15] L. C. Jaw, "Method for rapidly changing the power output of a turbine engine," U.S. patent no. 5,280,702, January 1994.
[16] L.-G. Sun, J.-G. Sun, H.-B. Zhang, and J.-K. Wang, "Augmented linear quadratic regulator controller design based on nonlinear integrated helicopter/engine model," Journal of Aerospace Power, vol. 25, no. 2, pp. 471-476, 2010.

[17] J. Wang, Z. Ye, and Z. Hu, "Nonlinear control of aircraft engines using a generallized gronwall-bellman lemma approach," Journal of Engineering for Gas Turbines and Power, vol. 134, Article ID 094502, pp. 1-6, 2012.

[18] J. J. Howlett, "UH-60A black hawk engineering simulation program: volume 1: mathematical model," NASA166309, 1981.

[19] M. G. Ballin, "Validation of a real-time engineering simulation of the UH-60A helicopter," Tech. Rep. NASA-TM-88360, NASA, 1987.

[20] P. Shanthakumaran, J. Harding, M. Kuehn, and D. Monroe, "Flight simulation model application for AH-64A Apache engine integration," in Proceedings of the 49th AHS International Annual Forum, St. Louis, Mo, USA, May 1993.

[21] W. Yao, Research on integrated modeling, control and optimization of turboshaft engine/rotor [Ph.D. thesis], Nanjing University of Aeronautics and Astronautics, Nanjing, China, 2008.

[22] H. Zhang, L. Sun, and J. Sun, "Robust disturbance rejection control design for integrated helicopter system/turbo-shaft engine," Acta Aeronautica et Astronautica Sinica, vol. 31, no. 5, pp. 883-892, 2010.

[23] A. Duyar, Z. Gu, and J. S. Litt, "A simplified dynamic model of the T700 turboshaft engine," Journal of the American Helicopter Society, vol. 40, no. 4, pp. 62-70, 1995.

[24] J. J. Slotine and W. Li, Applied Nonlinear Control, Prentice Hall, Englewood Cliffs, NJ, USA, 1991.

[25] P. Apkarian, H. D. Tuan, and J. Bernussou, "Continuous-time analysis, eigenstructure assignment, and $\mathrm{H}_{2}$ synthesis with enhanced linear matrix inequalities (LMI) characterizations," IEEE Transactions on Automatic Control, vol. 46, no. 12, pp. 1941-1946, 2001.

[26] S.-J. Kim, Y.-H. Moon, and S. Kwon, "Solving rank-constrained LMI problems with application to reduced-order output feedback stabilization," IEEE Transactions on Automatic Control, vol. 52, no. 9, pp. 1737-1741, 2007.

[27] H.-S. Ko, J. Jatskevich, G. Dumont, and G.-G. Yoon, "An advanced LMI-based-LQR design for voltage control of gridconnected wind farm," Electric Power Systems Research, vol. 78, no. 4, pp. 539-546, 2008.

[28] Q.-G. Wang, C. Lin, Z. Ye, G. Wen, Y. He, and C. C. Hang, "A quasi-LMI approach to computing stabilizing parameter ranges of multi-loop PID controllers," Journal of Process Control, vol. 17, no. 1, pp. 59-72, 2007.

[29] G. D. Padfield, Helicopter Flight Dynamics: The Theory and Application of Flying Qualities and Simulation Modeling, AIAA Education Series, American Institute of Aeronautics and Astronautics, Reston, Va, USA, 2nd edition, 2007.

[30] T.-J. Zheng, X. Wang, X.-Q. Luo, and Q.-H. Li, "Modified method of establishing the state space model of aeroengine," Journal of Propulsion Technology, vol. 26, no. 1, pp. 46-49, 2005. 


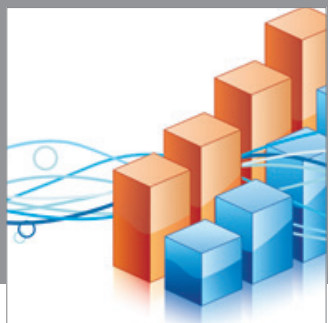

Advances in

Operations Research

mansans

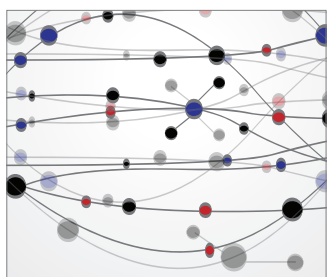

The Scientific World Journal
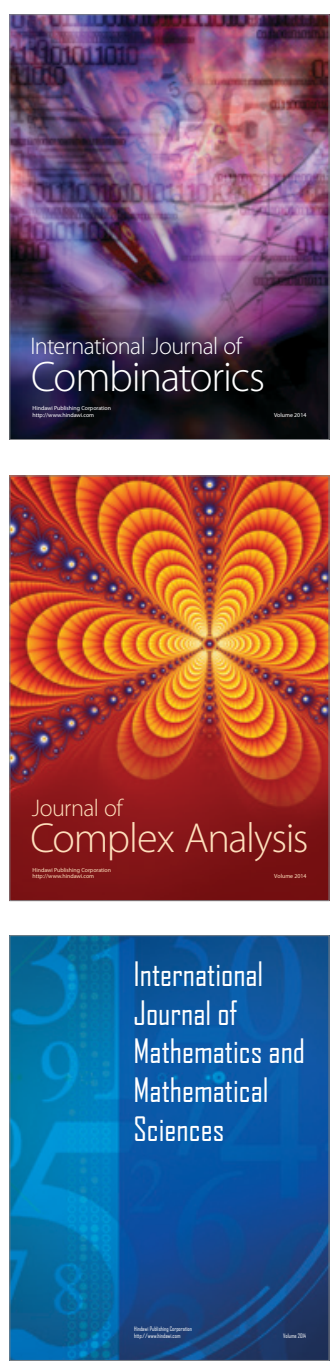
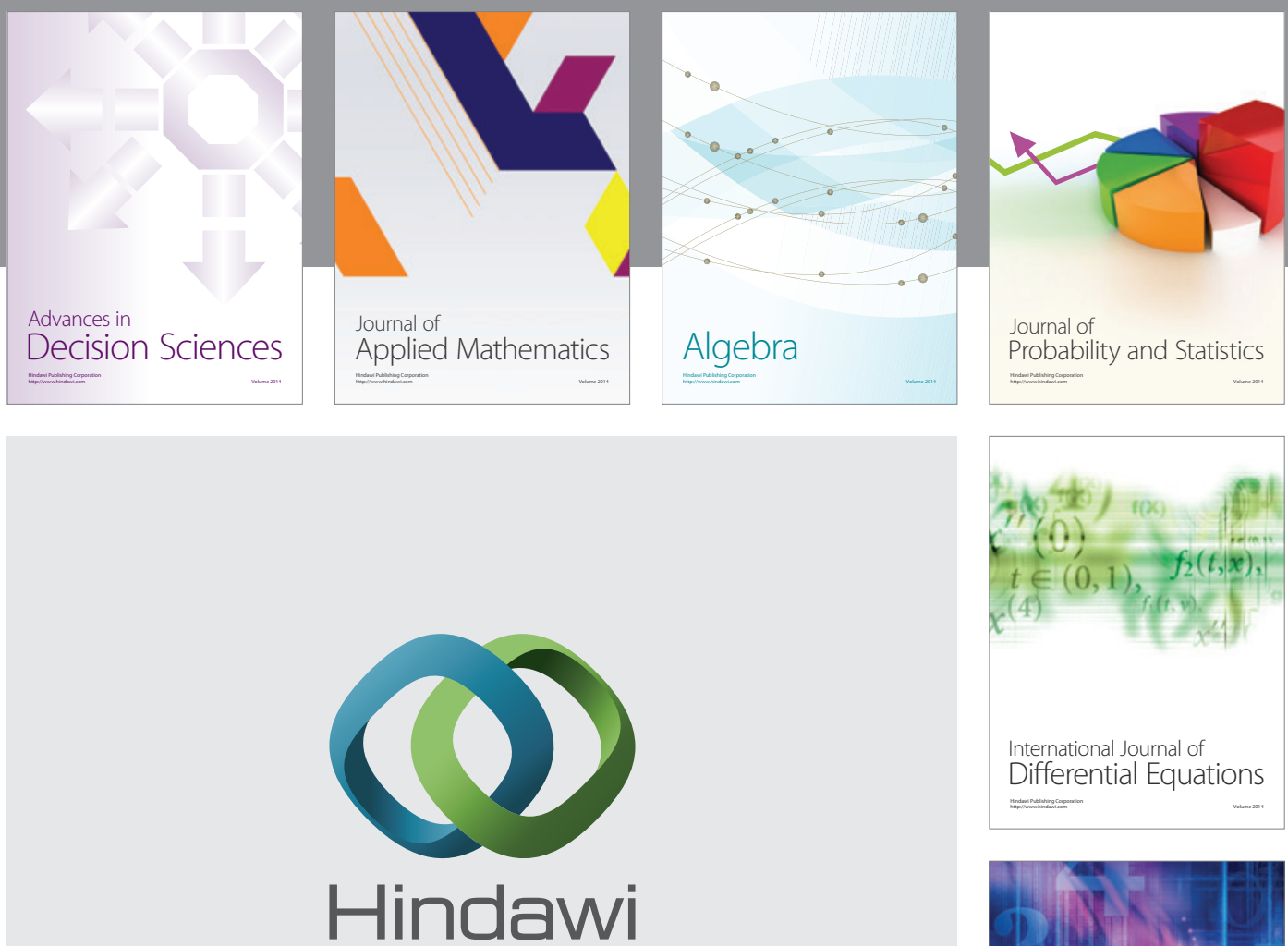

Submit your manuscripts at http://www.hindawi.com
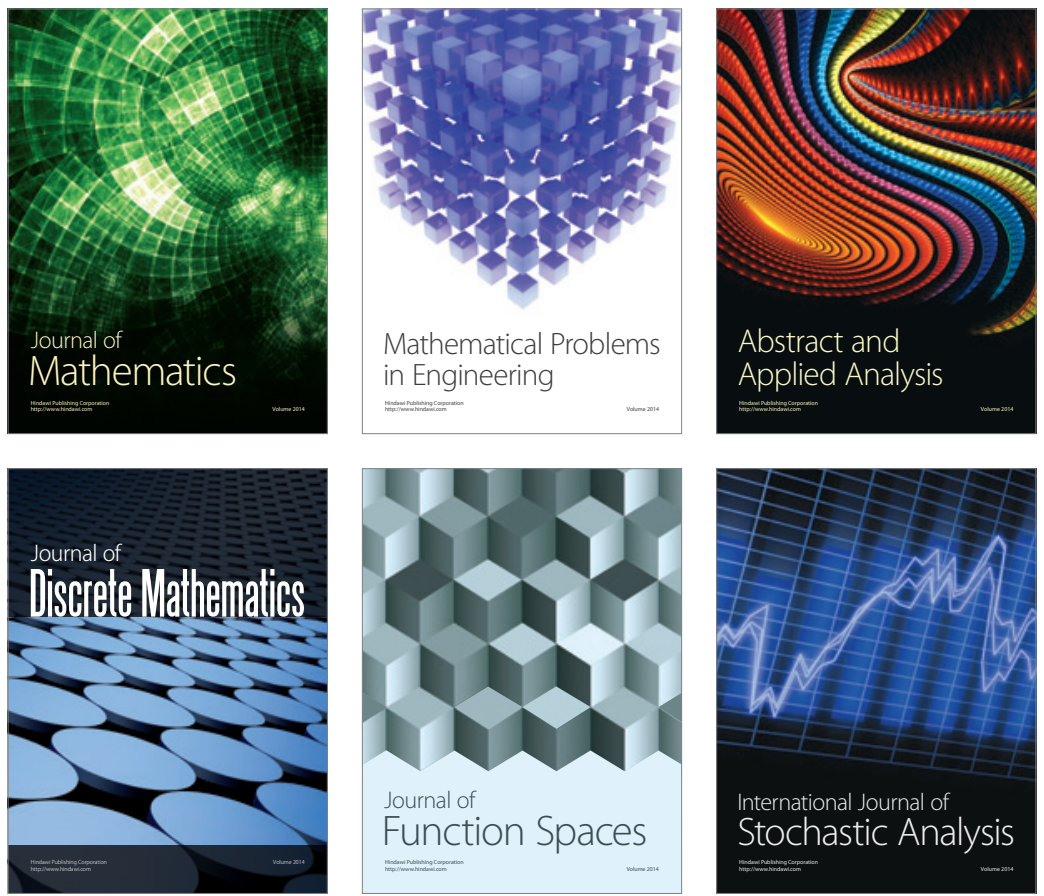

Journal of

Function Spaces

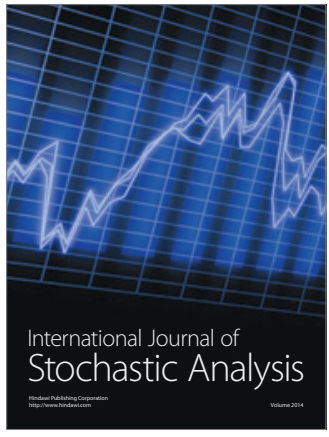

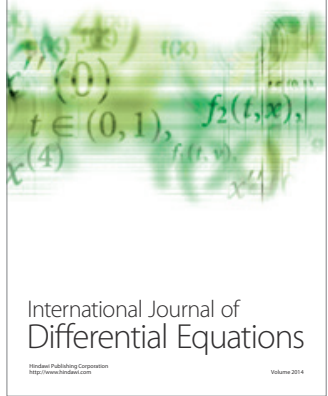
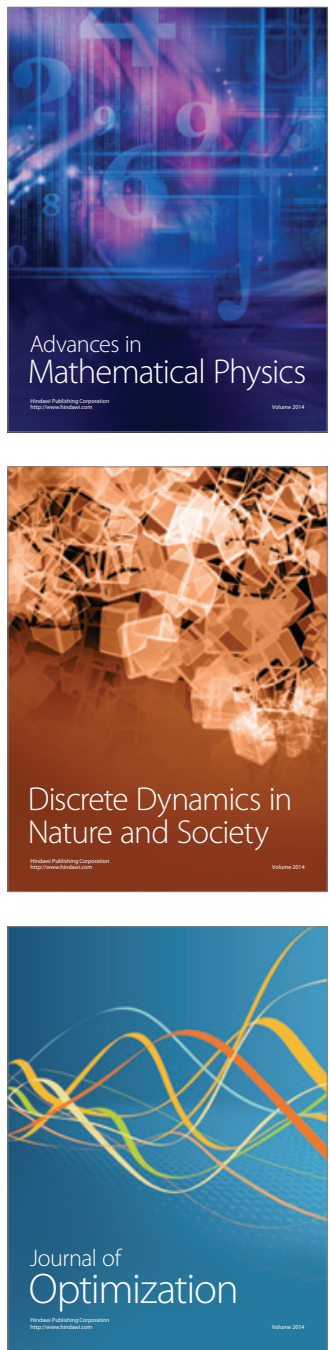